\title{
EVALUACIÓN DE RIESGOS DERIVADOS DE LOS ORGANISMOS MODIFICADOS GENÉTICAMENTE Y LA ADOPCIÓN DE MEDIDAS DE EMERGENCIA EN EL MARCO JURÍDICO DE LA UNIÓN EUROPEA
}

\section{EVALUATION OF RISKS DERIVED OF GENETICALLY MODIFIED ORGANISMS AND ADOPTION OF EMERGENCY MEASURES IN THE EUROPEAN UNION LEGAL FRAMEWORK}

\author{
IGNACIO BACHMANN-FUENTES \\ Profesor Asociado Departamento de Derecho Público \\ Universidad Pablo de Olavide \\ ribachmann@upo.es
}

Recibido: 20 de octubre de 2018 / Aceptado: 1 de febrero de 2019

RESUMEN: La Comisión Europea y el Tribunal de Justicia de la Unión Europea consideran que sólo puede adoptarse una medida de emergencia de conformidad a los artículos 34 del Reglamento (CE) № 1829/2003, 53 y 54 del Reglamento (CE) № 178/2002, ante la constatación de un riesgo grave derivado de los Organismos Modificados Genéticamente. Conforme al Derecho comunitario, el cual es fruto de una evolución normativa desarrollada durante las últimas décadas, esta verificación se debe realizar en el procedimiento de análisis de riesgos, específicamente durante la evaluación de riesgos. Por ello, el objetivo de este artículo es analizar los elementos de esta etapa, principalmente los conceptos de riesgo biotecnológico y el de incertidumbre científica, los cuales se encuentran íntimamente vinculados al principio de precaución. Por ello, se analiza también la interpretación y aplicación de este principio en la jurisprudencia del Tribunal de Justicia de la Unión Europea. 
RESUM: La Comissió Europea i el Tribunal de Justícia de la Unió Europea consideren que només es pot adoptar una mesura d'emergència de conformitat amb els articles 34 del Reglament (CE) № 1829/2003, 53 i 54 del Reglament (CE) № 178/2002, davant la constatació d'un risc greu derivat dels Organismes Modificats Genèticament. D'acord amb el Dret comunitari, el qual és fruit d'una evolució normativa desenvolupada durant les últimes dècades, aquesta verificació s'ha de realitzar en el procediment d'anàlisi de riscos, específicament durant l'avaluació de riscos. Per això, l'objectiu d'aquest article és analitzar els elements d'aquesta etapa, principalment els conceptes de risc biotecnològic i el d'incertesa científica, els quals es troben íntimament vinculats al principi de precaució. Per tant, s'analitza també la interpretació i aplicació d'aquest principi en la jurisprudència del Tribunal de Justícia de la Unió Europea.

ABSTRACT: The European Commission and the Court of Justice of the European Union consider that an emergency measure only can be adopted in accordance with Article 34 of Regulation (EC) No. 1829/2003, 53 and 54 of Regulation (EC) No. 178/2002, before the verification of a serious risk derived from Genetically Modified Organisms. According to Community law, which is the result of a regulatory evolution developed during the last decades, this verification must be realized in the risk analysis procedure, specifically during the risk assessment. Therefore, the objective of this article is to analyze the elements of this stage, mainly the concepts of biotechnological risk and scientific uncertainty, which are closely linked to the precautionary principle. Consequently, the interpretation and application of this principle is also analyzed in the jurisprudence of the Court of Justice of the European Union.

PALABRAS CLAVE: Evaluación de riesgos - OMG - medidas de emergencia principio de precaución - Unión Europea

PARAULES CLAU: Avaluació de riscos - OMG - mesures d'emergència principi de precaució - Unió Europea

KEYWORDS: Risks evaluation - GMO - emergency measures - Precautionary principle - European Union 
SUMARIO: I. Introducción. II. Evolución del Derecho Europeo de la bioseguridad. III. Principios jurídicos que rigen la materia. 1. Principio de precaución. a) El principio de precaución en el Derecho de la UE. 2. Principio de prevención. a) El principio de prevención en el Derecho Comunitario. IV. Concepto de riesgo biotecnológico. 1. El riesgo en el Derecho de la UE. 2. EI análisis de riegos de OMGs y sus etapas. V. Riesgos derivados de los OMGs. 1. Riesgos para la salud de los ecosistemas. 2. Riesgos para la salud humana y animal. VI. Conclusiones. VII. Bibliografía.

\section{INTRODUCCIÓN}

Tras la adopción de la Directiva (UE) 2015/412 del Parlamento y del Consejo, por la que se modificó la Directiva 2001/18/CE en lo que respecta a la posibilidad de que los Estados miembros restrinjan o prohíban el cultivo de Organismos Modificados Genéticamente (en adelante OMG) en su territorio, aparentemente la discusión sobre la conveniencia de estos cultivos y de sus efectos nocivos sobre la salud humana, animal y el medio ambiente, habría quedado zanjada.

En efecto, Estados como Francia, Polonia, Hungría, Grecia, Eslovenia, Alemania, Serbia, Croacia, Austria, Irlanda, Lituania, Letonia, Italia, Escocia y Gales, entre otros, prohibieron el cultivo de OMGs en sus territorios, mientras que otros como Bélgica e Inglaterra, optaron por restringirlos respecto de algunos territorios en particular ${ }^{1}$. A su vez, dentro de todos los Estados miembros de la UE, existen municipios o regiones que se han declarado libres de OMGs ${ }^{2}$.

España por su parte, que defiende un enfoque pragmático de la agricultura biotecnológica y de la importación de OMGs, se ha posicionado como el principal productor de la Unión Europea (en adelante UE), seguido de lejos por Portugal, Eslovaquia y República Checa ${ }^{3}$.

Según el Ministerio de Agricultura y Pesca, Alimentación y Medio Ambiente español, se estima que la superficie cultivada con OMG en el año 2017 llegó a las 124.227,47 hectáreas, siendo Aragón la Comunidad Autónoma que más

\footnotetext{
${ }^{1}$ En algunos casos, como el alemán, además del cultivo se ha prohibido la importación de OMGs a su territorio.

2 Vid. GMO Free Europe, Regions by Country. Recurso electrónico disponible en: <https://bit.ly/2ljNvh8> [Última consulta, 18 de abril de 2018].

${ }^{3}$ INTERNATIONAL SERVICE FOR THE ACQUISITION OF AGRI-BIOTECH APPLICATIONS. "Global Status of Commercialized Biotech/GM Crops: 2016". ISAAA Brief № 52, Ithaca, 2016, p. 74-75.
} 
superficie dedicó al cultivo de estos organismos (49.608,47 ha.), seguida por Cataluña (39.091,53 ha.) y Extremadura (13.976,06 ha.). Por otra parte, Galicia, Asturias, Cantabria y País Vasco registran 0 hectáreas ${ }^{4}$.

Es por ello que, en este contexto, cobra gran relevancia la sentencia del Tribunal de Justicia de la Unión Europea (en adelante TJUE) en el procedimiento penal "Fidenato y otros contra Italia" de 13 de septiembre de 2017 quien, conociendo de una cuestión prejudicial planteada por el Tribunal de Udine mediante la cual se solicitó interpretar los artículos 34 del Reglamento (CE) 1829/2003 y 53 y 54 del Reglamento (CE) 178/20025 , con el objeto de resolver si la medida de emergencia adoptada por el Gobierno italiano se ajustaba o no a estas disposiciones ${ }^{6}$.

La prohibición recaía sobre el cultivo de la variedad de maíz MON810 que había sido previamente autorizada por la CE. La medida fue decretada en base al informe científico del Consiglio per la Ricerca e la Sperimentazione in Agricoltura (actual CREA) y del Istituto Superiore per la Protezione e la Ricerca Ambientale (cuyas siglas son ISPRA), titulado "Revisión de la evidencia científica posterior a 2009 sobre los impactos del cultivo de maíz MON 810, con un examen particular de los efectos sobre organismos no objetivo y sobre la persistencia de la toxina Bt en el medio ambiente" por el que se concluyó que el maíz MON 810 tendrá un impacto sobre los parásitos de $O$. Nubilalis, que podría modificar las poblaciones de lepidópteros no objetivo y podría favorecer el desarrollo de parásitos secundarios, potencialmente dañinos para otros cultivos ${ }^{7}$.

El Gobierno italiano solicitó en abril de 2013 a la Comisión Europea (en adelante CE) que adoptara una medida de emergencia prevista en el mencionado artículo 34 del reglamento 1829/2003, con el objetivo de prohibir el cultivo de ese maíz.

\footnotetext{
4 Vid. MINISTERIO DE AGRICULTURA Y PESCA, ALIMENTACIÓN Y MEDIO AMBIENTE. Recurso electrónico disponible en: <https://bit.ly/2J23YmP> [Última consulta, 16 de abril de 2018].

${ }_{5}^{5}$ Véase el texto completo de la sentencia en InfoCuria: <https://bit.ly/2w0mdXU> [Última consulta, 9 de mayo de 2018].

${ }^{6}$ En cuanto a la aplicación en este caso de la Directiva 2015/412, el TJUE resolvió que era improcedente, primero por ratione temporis y luego, porque los motivos que en ella se establecen (de política agrícola o las repercusiones socioeconómicas, entre otras), "no pueden invocarse, ni sobre la base de dicha Directiva ni en nombre de un principio de cautela entendido en sentido amplio, para justificar la inobservancia efectiva del tenor del artículo 34 del Reglamento № 1829/2003. Este enfoque sería contrario a la redacción de esa disposición, que está clara, y al principio de legalidad antes descrito". Párrafos 83 y 84.

7 DECRETO 12 luglio 2013, Gazzetta Ufficiale della Republica Italiana.
} 
En mayo de ese mismo año, la CE contestó que, tras haberse realizado una evaluación de los datos aportados, consideró que no se había demostrado la existencia de una urgencia para adoptar medidas con arreglo a los artículos 53 y 54 del Reglamento 178/2002.

En efecto, a petición de la CE, la Autoridad Europea de Seguridad Alimentaria (EFSA, por sus siglas en inglés) emitió un dictamen pronunciándose sobre la evidencia científica que motivó dicho Decreto, precisando que:

El Panel OMG concluye que, sobre la base de la documentación presentada por Italia, no existen pruebas científicas específicas, en términos de riesgo para la salud humana y animal o el medio ambiente, que respalden la notificación de una medida de emergencia con arreglo al artículo 34 del Reglamento (CE) 1829/20038.

En definitiva, el Panel OMG consideró que sus conclusiones anteriores sobre la evaluación del riesgo en relación con el maíz MON 810 no se habían visto alteradas por los nuevos antecedentes científicos aportados por el Estado italiano y, por tanto, seguían siendo aplicables.

Claramente, basado en este dictamen científico de EFSA el Abogado General Michal Bobek indicó en su informe que:

De la jurisprudencia del Tribunal de Justicia se desprende que, con arreglo al principio de cautela, la «incertidumbre sobre el riesgo» no equivale a meras dudas generales. Deben identificarse riesgos concretos para la salud humana o el medio ambiente, respaldados por una mínima cantidad de estudios científicos serios e independientes. No basta con el temor a un riesgo o con el riesgo de riesgo ${ }^{9}[\ldots]$ El artículo 34 del Reglamento (CE) 1829/2003, interpretado a la luz del principio de cautela, permite a los Estados miembros adoptar medidas de emergencia únicamente si pueden demostrar, además de la emergencia, una situación que puede presentar un riesgo importante que ponga en peligro de manera manifiesta la salud humana, la sanidad animal o el medio ambiente ${ }^{10}$.

\footnotetext{
${ }^{8}$ EUROPEAN FOOD SAFETY AUTHORITY, "Scientific Opinion on a request from the European Commission related to an emergency measure notified by Italy on genetically modified maize MON810 according to Article 34 of Regulation (EC) № 1829/2003. EFSA Journal, 2013, Vol. 11, № 9, p. 6.

9 . La expresión "riesgo de riesgo" se ha recogido textualmente del informe.

10 Párrafo 148 del citado informe.
} 
Es decir, tanto el artículo 34 del Reglamento (CE) 1829/2003 como el artículo 53.1 del Reglamento (CE) 178/2002, establecen como requisito de aplicación de estas medidas de emergencia, la concurrencia de un riesgo importante o grave. Esto significa que, al mismo tiempo, se trataría también de un requisito de aplicación del principio de precaución que, como se verá más adelante, parte de la doctrina así lo entiende.

Por otra parte, el TJUE reprodujo en su sentencia la argumentación desarrollada en los casos acumulados "Monsanto y otros" (C-58/10 a C-68/10, EU:C:2011:553), estableciendo que:

No constituye una motivación válida para las medidas de protección adoptadas en virtud del mencionado artículo 34 una concepción del riesgo puramente hipotética, basada en meras suposiciones aún no verificadas científicamente. Por el contrario, tales medidas de protección, pese a su carácter provisional y preventivo, sólo pueden adoptarse sobre la base de una evaluación de los riesgos lo más completa posible, dadas las circunstancias concretas del caso de que se trate, que demuestre que dichas medidas son necesarias ${ }^{11}$.

En definitiva, el TJUE resolvió que:

La Comisión Europea no está obligada a adoptar medidas de emergencia con arreglo a este último artículo cuando un Estado miembro le informa oficialmente, en virtud del artículo 54, apartado 1 , de este último Reglamento, de la necesidad de adoptar esas medidas, si no es evidente que un producto autorizado por el Reglamento №1829/2003 o de acuerdo con lo dispuesto en él pueda constituir un riesgo grave para la salud humana, la sanidad animal o el medio ambiente.

Una argumentación muy similar planteó el Abogado General Bobek al evacuar su informe en el asunto C-528/16 caratulado Paysanne y otros contra Ministro de Agricultura de Francia -el cual se refiere a los OMG obtenidos mediante técnicas o métodos de mutagénesis y en el que se dictó una interesante sentencia- en el que planteó los requisitos para la correcta aplicación del principio de cautela ${ }^{12}$ :

\footnotetext{
11 Vid. Párrafo 51 de la sentencia.

12 En esta decisión, el TJUE resolvió que los organismos obtenidos mediante técnicas o métodos de mutagénesis que no han venido siendo utilizados convencionalmente (como es la técnica
} 
En primer lugar, la identificación de las consecuencias negativas que pueden tener para la salud las sustancias o los alimentos de que se trate y, en segundo lugar, un análisis global del riesgo para la salud basado en los datos científicos más fiables de que se disponga y en los resultados más recientes de la investigación internacional ${ }^{13}$.

Por otra parte, cabe hacer presente que el TJUE resolvió en el caso de Fidenato $y$ otros, que las medidas provisionales de gestión del riesgo que pueden adoptarse sobre la base de este principio y las medidas de emergencia del artículo 34 del Reglamento № 1829/2003 no forman parte del mismo régimen. Es decir, el Tribunal disocia los reglamentos analizados y limita la aplicación del principio de cautela solo a las medidas provisionales de gestión del riesgo:

...Se desprende del artículo 7 del Reglamento № 178/2002 que la adopción de estas medidas provisionales está sujeta al requisito de que una evaluación de la información disponible muestre la posibilidad de que se produzcan efectos nocivos sobre la salud, aunque siga existiendo incertidumbre científica. En cambio, el artículo 34 del Reglamento № 1829/2003 permite recurrir a las medidas de emergencia cuando sea «evidente» que un producto autorizado por el Reglamento puede constituir un riesgo «grave» para la salud humana, la sanidad animal o el medio ambiente.

Estas argumentaciones son las que motivan el presente artículo y hacen necesario analizar dos conceptos jurídicos que son claves en la evaluación de riesgos: riesgo biotecnológico e incertidumbre científica, los cuales se encuentran íntimamente relacionados con el principio de precaución. A su vez, estos elementos serán cotejados con los resultados de numerosos estudios científicos serios e independientes que dan cuenta de riesgos concretos. De esta manera, podría avanzarse en la comprensión del verdadero sentido y alcance de las normas reglamentarias citadas que facultan a los Estados miembros y a la CE para adoptar medidas de emergencia.

CRISPR) y para los que no se dispone de una amplia experiencia de utilización segura, quedan comprendidos en el ámbito de aplicación de la Directiva 2001/18 y, por lo tanto, están sujetos a las obligaciones que derivan de ella.

13 Vid. Párrafo 49. Observaciones del Abogado General, Asunto C-528/16: <https://bit.ly/2HPM9Hs> [Última consulta: 9 de mayo de 2018]. 
En cuanto a las investigaciones científicas que aquí se abordarán, han advertido de los potenciales riesgos derivados del cultivo de OMGs realizadas principalmente en países de la UE, haciendo de manera complementaria algunas referencias a experiencias relevantes documentadas en otras partes del mundo. Estos y otros estudios han motivado la adopción de medidas de emergencia prohibitivas o restrictivas del cultivo o importación de estos organismos en los distintos países miembros.

Con el fin de facilitar su comprensión, se realizará un análisis de la evolución del Derecho de la bioseguridad en la UE, así como de los conceptos y principios fundamentales de esta materia, principalmente a la luz de la Jurisprudencia del TJUE.

\section{EVOLUCIÓN DEL DERECHO EUROPEO DE LA BIOSEGURIDAD}

En una primera etapa, las normas tuvieron como propósito implementar un riguroso enfoque precautorio ante los desconocidos efectos que pudieran derivarse de la manipulación y liberación de los OMG. Es por esto por lo que no existía en ellas una relación de los riesgos derivados.

Gran Bretaña fue el primer país dentro del espacio europeo que asumió el debate social en torno a los riesgos biotecnológicos y en establecer una normativa específica para estas nuevas actividades. Fue a partir de la década de los $70 \mathrm{del}$ siglo XX que el gobierno británico asumió su responsabilidad frente a los avances de la biotecnología moderna, con la constitución del Genetic Modification Advisory Group (GMAG), órgano consultivo gubernamental que en 1978 se convirtió en la instancia administrativa central a la que debían dirigirse los proyectos de trabajo con OMG. Fue en ese año cuando se publicó la primera norma específica respecto al control de los riesgos derivados de la ingeniería genética, The Health and Safety (Genetic Manipulation) Regulations ${ }^{14}$.

En esta norma, se introdujeron los controles estrictos recomendados en el informe presentado por el grupo de trabajo dirigido por Lord Ashby y en el informe

${ }_{14}$ MELLADO RUIZ, L. "Derecho de la biotecnología vegetal. La regulación de las plantas transgénicas". Instituto Nacional de Administración Pública, Madrid, 2002, p. 228. 
Williams. Así, cualquier actividad que implicaba la manipulación genética debía ser notificada al GMAG y al Health and Safety Executive (HSE) $)^{15}$.

En 1984, el GMAG pasó a llamarse Advisory Committee on Genetic Modification (ACGM), y hoy en día se denomina Scientific Advisory Committee on Genetic Modification (Contained Use), el que sigue siendo un organismo importante en el sistema consultivo británico sobre bioseguridad ${ }^{16}$.

Durante la década de los 80 , las técnicas de modificación genética fueron desarrolladas dentro de procesos industriales, lo que hizo ver al enfoque muy precautorio adoptado en el Reglamento de 1978 como excesivamente restrictivo y desproporcionado en relación con los riesgos revelados por los conocimientos adquiridos hasta entonces. El Reglamento de 1978 se consideró obsoleto y en consecuencia fue reemplazado por el Genetic Modification Regulations de 1989. Al igual que el Reglamento de 1978, esta norma solo era aplicable a la salud y a la seguridad de las personas y no a la protección del medio ambiente, aunque había un acuerdo entre la Health and Safety Commision (HSC) y la ACGM con la industria de evaluar también los riesgos ambientales ${ }^{17}$.

En una segunda etapa, comenzaron a vislumbrarse los riesgos derivados del consumo y liberación de los OMGs en el medio ambiente. Fue así como en el año 1986, la Organización para la Cooperación y el Desarrollo Económicos, (OCDE) publicó el informe titulado Recombinant DNA Safety Considerations. Safety considerations for industrial, agricultural and environmental applications of organisms derived by recombinant DNA techniques ${ }^{18}$, en el cual se aludía a ciertas consideraciones de seguridad asociadas a las aplicaciones industriales a gran escala de OMGs, dentro de las cuales enumeraba los siguientes riesgos:

i. Riesgo de infección: el potencial de enfermedad en el hombre, los animales y las plantas después de la exposición al organismo vivo o virus;

${ }^{15}$ Vid. PARLAMENTO DEL REINO UNIDO. "A brief outline history of the legislation on health and safety aspects of GMOs". Recurso electrónico disponible en: <http://bit.ly/2ftjFpJ> [Última consulta, 16 de febrero de 2018].

${ }^{16}$ MELLADO RUIZ, L. "Derecho de la biotecnología vegetal...", cit. p. 228.

17 Vid. Página web del ACGM: <https://bit.ly/2QOqofK> [Última consulta, 5 de junio de 2018].

18 Vid. p. 27 del citado informe. 
ii. El efecto biológico tóxico, alergénico u otro del organismo o de células no viables, sus componentes o sus productos metabólicos de origen natural;

iii. El efecto biológico tóxico, alergénico u otro del producto expresado por el organismo;

iv. Los efectos ambientales.

Respecto de estos últimos, planteaba consideraciones específicas sobre los microorganismos, consideraciones específicas para plantas y consideraciones específicas sobre los animales.

En este periodo, el primer país en dictar una ley específica sobre seguridad de la biotecnología fue Dinamarca, que en el año 1986 promulgó su Act on Environment and Genetic Engineering, que prohibió la liberación intencional de $\mathrm{OMG}^{19}$. El Ministro de Medio Ambiente estaba facultado para eludir esta prohibición bajo circunstancias extraordinarias, por lo que era posible obtener un permiso para la utilización confinada de OMG previa aprobación de parte de esta autoridad y, todos los alimentos que contenían o se componían de OMG, requerían de una aprobación ${ }^{20}$.

En el plano Comunitario, las Directivas 90/219/CEE sobre utilización confinada de microorganismos modificados genéticamente y 90/220/CEE sobre la liberación intencional en el medio ambiente de organismos modificados genéticamente, la cual, atendiendo a estas consideraciones de bioseguridad requería la siguiente información del OMG:

11. Rasgos patológicos, ecológicos y fisiológicos de los organismos:

a) clasificación de los riesgos, de conformidad con las normas comunitarias vigentes relativas a la protección de la salud humana y / o del medio ambiente;

b) período de generación en ecosistemas naturales, ciclo reproductivo sexual y asexual;

19 DURANT, J. BAUER, M. GASKELL, G. "Biotechnology in the Public Sphere: A European Sourcebook". NMSI Trading Ltd., Londres, 1998, p. 31.

${ }^{20}$ Esta ley fue reemplazada en 1991 por la ley № 356 de 6 de junio, la cual tenía como objetivo de cumplir con las Directivas 90/219 y 90/220. Cuando esta última Directiva fue derogada por la Directiva 2001/18, la ley danesa de 1991 fue modificada por la ley № 384 de 6 de junio de 2002. 
c) información sobre la supervivencia, incluidas la estacionalidad la capacidad para fomentar estructuras de supervivencia: por ejemplo, semillas, esporas o esclerotos;

d) patogenicidad: infecciosidad, toxicidad, virulencia, alergenicidad, portador (vector) de patógeno, vectores posibles, gama de huéspedes incluidos los organismos que no sean objeto de la investigación. Posible activación de virus latentes (provirus). Capacidad para colonizar otros organismos;

e) resistencia a los antibióticos y uso potencial de dichos antibióticos en seres humanos y organismos domésticos con fines profilácticos y terapéuticos;

f) participación en procesos ambientales: producción primaria, ciclos de nutrientes, descomposición de la materia orgánica, respiración, etc. ${ }^{21}$.

Así, llegamos a la tercera y actual etapa, que se inició con la moratoria de facto impuesta en la Unión Europea, comprendida entre los años 1999 y 2004 como consecuencia de las discrepancias existentes entre algunos Estados miembros y la $\mathrm{CE}^{22}$. En este periodo se dictaron las principales normas comunitarias sobre bioseguridad y seguridad alimentaria, tanto Directivas como Reglamentos.

La Directiva 2001/18/CE sobre la liberación intencional en el medio ambiente de organismos modificados genéticamente y por la que se deroga la Directiva 90/220/CEE, recogió los cambios derivados de la revisión de la normativa existente y se profundizó en aspectos como la necesidad de establecer procedimientos y criterios armonizados para la evaluación caso por caso de los potenciales riesgos derivados de la liberación de OMGs, abogando por un método común de evaluación basado en informes científicos independientes. $A$ su vez, se establecieron una serie de objetivos de seguimiento tras la liberación

\footnotetext{
21 Vid. Anexo II. II.

22 GONZÁLEZ VAQUÉ, L. "EI Derecho de la UE relativo a los organismos modificados genéticamente: la Comisión Europea cambia de estrategia para permitir, restringir o prohibir su cultivo". Revista de Derecho y Genoma Humano, 2010, № 33, p. 3.
} 
o comercialización de los $\mathrm{OMGs}^{23}$. Sin perjuicio de ello, las exigencias antes indicadas de la Directiva 90/220/CEE, fueron mantenidas por la nueva norma ${ }^{24}$.

\section{PRINCIPIOS JURÍDICOS QUE RIGEN LA MATERIA}

Como resultado de la evolución del derecho de la biotecnología, en la actual legislación comunitaria sobre bioseguridad y seguridad alimentaria, se consagran - tanto en el Derecho originario como en el derivado - una serie de principios jurídicos que deben ser observados en todo momento. A su vez, la incorporación de los conceptos de riesgo e incertidumbre, así como otros relevantes en la materia, se encuentran íntimamente ligados con estos principios, tanto para su interpretación como para su aplicación.

Los principios más relevantes en esta materia son: el de precaución, de prevención, paso a paso, caso por caso y equivalencia sustancial. De todos ellos, sin duda, los más relevantes para el análisis que aquí se plantea, son los de precaución y prevención, los cuales paso a desarrollar someramente.

\section{Principio de precaución o cautela}

ROBERTO ANDORNO afirma que, para hablar de este principio, debe partirse con una referencia a la virtud clásica de prudencia, especialmente en su forma de prudencia política, la cual proporciona un útil marco conceptual para su mejor comprensión. Esto porque, finalmente, este principio jurídico consiste nada menos que en recurrir a la prudencia cuando se trata de tecnologías que puedan ser potencialmente dañinas para la salud pública y el medio ambiente ${ }^{25}$.

ADELA CORTINA coincide en que este principio es una nueva forma de prudencia que exige actuar para conocer, puesto que en un contexto en el cual

23 ESCAJEDO SAN EPIFANIO, L. "'Principio de precaución y riesgos ambientales, especialmente los asociados a los OMG", en Carlos Romeo Casabona (Coord.), Principio de precaución, Biotecnología y Derecho. Cátedra Interuniversitaria Fundación BBVA-Diputación Foral de Bizkaia de Derecho y Genoma Humano, Edit. Comares, Granada, 2004, p. 160.

${ }^{24}$ Vid. Anexo III A, Información requerida en las notificaciones de liberación de OMG distintos de las plantas superiores, Apartado II.

${ }^{25}$ ANDORNO, R. "The Precautionary Principle: A New Legal Standard for a Technological Age". Journal of International Biotechnology Law", 2004, Vol. 1, No 1, p.11. 
falta conocimiento, existe el deber de deliberar ${ }^{26}$. En ningún caso, la prudencia debe ser entendida como una falta de voluntad para actuar o como falta de valor para enfrentar a los nuevos desafíos. Por el contrario, este término se emplea en este contexto con su significado clásico de capacidad de discernir la vía de acción más adecuada. Para Aristóteles, la prudencia es una de las virtudes más importantes de las autoridades políticas, hasta el punto de que consideraba a la política como la forma más elevada de la prudencia, ya que está dirigida al bien común de la sociedad y no a intereses puramente individuales ${ }^{27}$.

Encontramos su origen jurídico en el Vorsorgeprinzip alemán que, traducido literalmente al castellano, significa principio de previsión, y al inglés, significa foresight o taking care, aunque también incorpora nociones de buen manejo y de las mejores prácticas en gestión ambiental, incluso en ausencia de riesgo ${ }^{28}$.

En el Derecho internacional pueden encontrarse una serie de definiciones, las que difieren en algunos aspectos. A modo de ejemplo, el Convenio sobre la Diversidad Biológica indica en su preámbulo que:

Observando también que cuando exista una amenaza de reducción o pérdida sustancial de la diversidad biológica no debe alegarse la falta de pruebas científicas inequívocas como razón para aplazar las medidas encaminadas a evitar o reducir al mínimo esa amenaza.

Con el fin de aunar criterios y facilitar su comprensión como principio jurídico positivo, la doctrina ha ido enunciando los elementos esenciales de la precaución:

- Temor a un daño potencial a la salud o al medio ambiente de una acción u omisión humana y estos se consideran irreparables e irreversibles;

- Incertidumbre científica acerca del acaecimiento del daño o de la relación de causalidad entre la conducta observada y el daño;

26 CORTINA, A. "Fundamentos filosóficos del principio de precaución", en Carlos Romeo Casabona (Coord.), Principio de precaución, biotecnología y Derecho. Cátedra Interuniversitaria Fundación BBVA-Diputación Foral de Bizkaia de Derecho y Genoma Humano, Edit. Comares, Granada, 2004, p. 6.

${ }^{27}$ ANDORNO, R. "The Precautionary Principle..." cit. p. 11.

${ }^{28}$ ANDORNO, R. "The Precautionary Principle..." cit. p. 13. 
- Ejercicio de una acción anticipada, conforme a la naturaleza y alcance del daño ${ }^{29}$.

En cuanto al primer elemento, CORTINA precisa que este principio no opera respecto de cualquier daño, sino que solo respecto de aquellos graves 0 irreversibles en un contexto de incertidumbre científica, e invita a los industriales a controlar a priori la peligrosidad de sus productos ${ }^{30}$. Como se verá más adelante, pareciera que esta categoría de daños no se ajusta a la realidad científica, sino que dicho principio debería operar respecto de todo daño derivado de los OMGs.

Respecto del segundo, LASCOUNE advierte que este principio demanda para su aplicación un ejercicio activo de la duda, ya que su lógica no apunta al riesgo -del cual se encarga la prevención- sino que se proyecta hacia la incertidumbre ${ }^{31}$. Ahora bien, se plantea la necesidad de acreditar y contrastar la situación de incertidumbre o incerteza, cuya carga -según ESTEVE PARDO- recae sobre el órgano que apela al principio de precaución y que en base a él podría adoptar alguna medida de emergencia ${ }^{32}$. A mi juicio, esta obligación constituiría una suerte de probatio diabolica, toda vez que consiste en probar un hecho 0 circunstancia negativa: que no existe certidumbre o certeza.

En cuanto a su aplicación, GONZÁLEZ VAQUÉ advierte que la integración de este principio en medidas jurídicas resulta complicada, puesto que debe recurrirse a este principio cuando no puede establecerse la relación de causalidad entre un daño o un perjuicio y su causa, existiendo solo una presunción generalmente basada sobre conceptos estadísticos y probabilidades $^{33}$. En realidad, más que establecerse una presunción de riesgo, lo que este principio exige por parte de la autoridad competente, es la

29 Vid. BERGEL, S. BERGEL, S. "Precaución, principio de", en Enciclopedia de Bioderecho y Bioética, Cátedra Interuniversitaria Fundación BBVA-Diputación Foral de Bizkaia de Derecho y Genoma Humano, Universidad de Deusto y Universidad del País Vasco, Edit. Comares, Tomo II, Granada, 2011, p. 1300.

${ }^{30}$ CORTINA, A. Fundamentos filosóficos del principio de precaución...”, cit. p. 6.

${ }^{31}$ LASCOUNE, P. Citado por BERGEL, S. "Enciclopedia de Bioderecho y Bioética..." cit. p. 1297. 32 ESTEVE PARDO, J. "La operatividad del principio de precaución en materia ambiental", en EI principio de precaución y su proyección en el derecho administrativo español. Manuales de formación continuada 26, Consejo General del Poder Judicial, Madrid, 2005, p. 204.

${ }^{3}$ GONZÁLEZ VAQUÉ, L. "La aplicación del principio de precaución en la legislación alimentaria. ¿Una nueva frontera de protección al consumidor?”. Estudios sobre Consumo, № 50, 1999, p. 15. 
ponderación de los antecedentes aportados -conforme a las reglas de la sana crítica- y evaluar la posible existencia de una relación entre el daño (efecto) y una determinada acción (causa), pese a la incertidumbre científica.

\section{a) El principio de precaución en el Derecho de la UE}

Este principio fue incorporado en la normativa comunitaria en la década de los noventa del siglo XX en el denominado Derecho originario. La primera referencia explícita se hizo en el Tratado de Maastricht: "La política de la Comunidad sobre el medio ambiente se basará en el principio de precaución y en los principios de que deben adoptarse medidas preventivas que el daño al medio ambiente debe, como prioridad, rectificarse en su origen $[\ldots]^{\prime 34}$.

El actual Tratado de Funcionamiento de la Unión Europea (TFUE) dispone que:

La política de la Unión en el ámbito del medio ambiente tendrá como objetivo alcanzar un nivel de protección elevado, teniendo presente la diversidad de situaciones existentes en las distintas regiones de la Unión. Se basará en los principios de cautela y de acción preventiva ${ }^{35}$.

En la Directiva 2001/18 CE se indica: "Se ha tenido en cuenta el principio de cautela a la hora de redactar la presente Directiva y debe tenerse en cuenta cuando ésta se aplique"36. Por su parte, el Reglamento 178/2002 establece que: "[...] si la posibilidad de efectos dañinos sobre la salud es identificada pero la incertidumbre persiste, se pueden adoptar las medidas de gestión provisional del riesgo necesarias para asegurar el alto nivel de protección elegido en la Comunidad [...]"37.

En la Comunicación de la CE sobre este principio, se indica que este permite reaccionar rápidamente ante un posible peligro para la salud humana, animal o vegetal, o para proteger el medio ambiente. Así, en caso de que los datos científicos no permitan una determinación total del riesgo, este recurso permite,

\footnotetext{
34 Tratado de Maastricht, párrafo 31.

35 Artículo 191.2 del TFUE.

36 Vid. Considerando 8.

37 Artículo 7.1.
} 
por ejemplo, paralizar la distribución de productos que puedan entrañar un peligro para la salud o incluso proceder a su retirada del mercado ${ }^{38}$.

Dicha Comunicación recalca que, aunque las medidas tengan un carácter provisional, deben mantenerse mientras los datos científicos sigan siendo incompletos, imprecisos o no concluyentes y mientras se considere que el riesgo es lo suficientemente importante. Las medidas basadas en este principio deben ser revisadas y si procede modificarlas en función de los resultados de la investigación científica y del seguimiento de su impacto ${ }^{39}$.

\section{Principio de prevención}

A pesar de que habitualmente precaución y prevención se utilizan indistintamente, es importante hacer la diferenciación. En la prevención, las relaciones entre causas y efectos de determinados procesos o acciones pueden ser mínimamente conocidas, reversibles y de cierta manera, esperables. Se puede prevenir y por tanto intentar contrarrestar las consecuencias negativas de una determinada obra, por ejemplo, mediante una evaluación de impacto ambiental. Sin embargo, la magnitud o irreversibilidad de los efectos y la incertidumbre de los riesgos a los que alude la precaución son de una mayor extensión, por cuanto la mayor parte de los efectos que de ellos puedan surgir, no puedan ser identificados con anterioridad ${ }^{40}$.

Así entonces, la prevención puede considerarse como una conducta racional frente a un mal que mediante el conocimiento científico puede ser objetivado y medido, por tanto, se mueve dentro de las certidumbres de la ciencia. En cambio, la precaución enfrenta a la incertidumbre, específicamente, a la incertidumbre de los conocimientos científicos en sí mismos ${ }^{41}$.

\footnotetext{
${ }^{38}$ COMUNICACIÓN "Sobre el recurso al principio de precaución", Bruselas, 2 de febrero de 2000. Recurso electrónico disponible en: <http://bit.ly/1MgCWRY> [Última consulta, 7 de junio de 2018].

39 Vid. Apartado 6.3 de la Comunicación.

40 TÁBARA, D; POLO, D; LEMKOW, L. "Precaución, riesgo y sostenibilidad en los organismos agrícolas modificados genéticamente". Política y Sociedad, 2003, Vol. 40, № 3, p. 99.

41 LLORET, E. "El principio preventivo y precautorio en el Derecho Ambiental: ¿a qué principio responde la evaluación del impacto ambiental?" Cartapacio de Derecho: Revista Virtual de la Facultad de Derecho, 2011, № 21, p. 14.
} 
El principio de prevención o de acción preventiva se basa en las estrategias de protección ambiental, es un principio fundamental del derecho ambiental el cual ha sido resumido por la doctrina en la conocida frase de más vale prevenir que curar. En términos simples, es necesario actuar antes que se produzcan los daños, a fin de evitar -a medida de lo posible- o al menos reducir en gran medida, el riesgo de tales daños. Y esto no sólo se debe a que el daño, una vez verificado, pueda resultar irreparable, ya que incluso cuando lo sean, las consecuencias tienen una considerable importancia económica ${ }^{42}$.

Para MELLADO RUIZ, en materia de bioseguridad, este principio es:

un precepto ineludible y axiomático de cualquier regulación ambiental y sanitaria, por la posible irreversibilidad de los daños o perjuicios, máxime tratándose de una actividad tecnocientífica en la que están implicados, nada más y nada menos, que los mismos fundamentos de la existencia, de la vida, propia y ajena ${ }^{43}$.

Por tanto -señala BERBEROFF- por muy graves y perjudiciales que puedan resultar determinados riesgos, una vez que son conocidos, la Administración responsable intentará evitar o disminuir los mismos a través de mecanismos preventivos oportunos ${ }^{44}$. En realidad, este principio se activa una vez conocidos los riesgos, incluso frente a aquellos considerados leves o menores.

\section{a) El principio de prevención en el Derecho Comunitario}

Según DE SADELEER, la política comunitaria sobre medio ambiente ha evolucionado progresivamente hacia un enfoque global y preventivo. Incluso, antes de ser incorporado formalmente en el Tratado Constitutivo de la Unión Europea, el principio preventivo jugó un papel preponderante en la política medioambiental comunitaria. El primer programa de acción del Consejo Europeo (de 22 de noviembre de 1973) estableció las bases de lo que se entiende

\footnotetext{
42 MANCINI PALAMONI, G. "Il Principio di Prevenzione". AmbienteDiritto.it- Revista Giuridica Telematica, 2014, p. 3.

43 MELLADO RUIZ, L. "Bioseguridad y Derecho: La administración ante los riesgos de la tecnología de la vida". Editorial Comares, Granada, 2004, p. 22.

${ }^{44}$ BERBEROFF AYUDA, D. "Incertidumbre científica y riesgo: cinco ideas fuerza a propósito del principio de precaución", en El principio de precaución y su proyección en el Derecho administrativo español". Manuales de formación continuada 26, Consejo General del Poder Judicial, Madrid, 2005, p. 27.
} 
actualmente por principio de prevención, en cuanto indica que "la mejor política de medio ambiente consiste en impedir la generación de contaminación y las perturbaciones en su origen, en lugar de actuar con posterioridad contra sus efectos"45. A este enfoque preventivo se le dio mayor énfasis en el Segundo programa de acción de las Comunidades Europeas en materia de Medio Ambiente del 17 de mayo de 1977, en el cual se introdujo lo siguiente:

Considerando, en particular, que en materia de reducción de contaminación y ruidos ambientales, ha de otorgarse prioridad a las medidas relativas a la protección de las aguas y a las de la contaminación del aire y que la lucha contra el ruido debe ser objeto de nuevas medidas; que conviene, además, reforzar el carácter preventivo de la política relativa al medio ambiente y conceder una atención especial a la protección y a la gestión racional del especio, del medio y de los recursos naturales ${ }^{46}$.

Actualmente, este principio se encuentra consagrado en el artículo 192 de TFUE. Asimismo, se encuentra recogido en diversas normas y descrito como principio rector en el preámbulo de la Directiva 2001/18/CE como principio de "acción preventiva"47. Por su parte, el Reglamento (CE) 178/2002 alude a este principio en diversas disposiciones, cobrando gran relevancia en la adopción de medidas de emergencia ${ }^{48}$.

\section{CONCEPTO DE RIESGO BIOTECNOLÓGICO}

Cabe partir refiriéndose al concepto de sociedad del riesgo que el sociólogo alemán ULRICH BECK acuñó para calificar a la sociedad capitalista occidental configurada después de la Segunda Guerra Mundial y de este modo, hacer referencia a una serie de efectos nocivos o nuevos riesgos derivados del desarrollo de la técnica y de los actuales sistemas de producción y consumo en las sociedades postindustriales ${ }^{49}$.

\footnotetext{
45 SADELEER, N. "Environmental Principles: From Political Slogans to Legal Rules". Oxford University Press, Nueva York, 2002, p. 68.

${ }^{46}$ Vid. SANCHEZ MUÑOZ, M. "Treinta años de actuación en materia medioambiental en la Unión Europea". Comunicación presentada en el Congreso Internacional de Ordenación del Territorio, Gijón, julio de 2001, p. 5.

47 Considerando 6 de la Directiva.

${ }^{48}$ A modo de ejemplo: artículos 3 № 12, 10, 14, 19, 20.3, 55.2 y 56.

${ }^{49}$ BECK, U. "La sociedad del riesgo. Hacia una nueva modernidad". Paidós Ibérica, Barcelona, 1986, p. 14.
} 
En su obra no interpreta el riesgo como una consecuencia colateral negativa controlable por las autoridades, sino como una característica elemental de las sociedades industriales contemporáneas y su incapacidad para prever, controlar, y distribuir de manera justa los riesgos ecológicos y sanitarios asociados al progreso tecnocientífico. En otras palabras, puede colegirse que la sociedad del riesgo es una sociedad basada en la desprotección, y el riesgo no es sino "el estar desprotegido en una situación determinada" 50 .

De hecho, Beck afirma que los riesgos son minimizados mediante cálculos, los cuales se normalizan jurídica y científicamente mediante comparaciones como «riesgos residuales o improbables» para así estigmatizar las protestas como «brotes de irracionalidad» ${ }^{51}$.

En este contexto, se han planteado diversos conceptos de riesgo, entre los cuales se encuentran los estadístico-probabilísticos que se basan en criterios tecnocientíficos y de carácter cuantitativo, en virtud de los cuales el riesgo se concibe como una propiedad objetiva de un evento o una actividad y que puede ser medido. Por otro lado, desde una perspectiva de las ciencias sociales el riesgo se considera un producto sociocultural; es decir, la definición misma de riesgo varía conforme al contexto histórico y cultural como, asimismo, se fundamente en convenciones sociales. De esta manera, el riesgo puede entenderse como la evaluación de la posibilidad de un efecto adverso como consecuencia de un peligro ${ }^{52}$.

Frente a estos riesgos derivados de los avances científicos y tecnológicos, la sociedad ha desarrollado sistemas de control de riesgos mediante la implementación de instrumentos científico-políticos. No obstante, diversas catástrofes medioambientales y sanitarias han puesto de manifiesto los límites de los mecanismos clásicos de evaluación y gestión de riesgos, lo que ha hecho patente la necesidad de abordar los problemas que acarrea el desarrollo

\footnotetext{
${ }^{50}$ MÉNDEZ, P. "Sobre el concepto de riesgo". Nómadas, revista crítica de Ciencias Sociales y Jurídicas, № 5, 2002. Recurso electrónico disponible en: <http://webs.ucm.es/info/nomadas/5/pmendez.htm> [Última consulta, 23 de septiembre de 2018].

51 BERGEL, S. "Precaución..." cit. p. 1296.

52 ESPLUGA, J. "Ulrich Beck i les dimensiones socials del risc". Medi ambient: Tecnología i cultura, № 24, 1999. Recurso electrónico disponible en: <http://www.gencat.cat/mediamb/revista/rev24-4.htm> [Última consulta, 3 de septiembre de 2018].
} 
tecnocientífico sobre el medio y las personas en base a un enfoque precautorio que sea capaz de desarrollar medidas adecuadas de control en contextos donde predomina la incertidumbre y no existe un conocimiento concreto sobre el riesgo futuro ${ }^{53}$.

En cuanto a los OMGs, la incertidumbre se refiere a aquellas situaciones en las cuales no existe evidencia científica concluyente sobre la seguridad o beneficios de estos organismos, cuando esta evidencia está incompleta o cuando no está disponible. Debido a la complejidad de los ecosistemas y a las dificultades para monitorear los OMG en el medio ambiente, podría tardarse años en demostrar sus efectos y dejar en ese intertanto desprotegida a la población ${ }^{54}$.

En efecto, en la evaluación de riesgos es necesario considerar la incertidumbre, lo que a su vez implica asumir que el comportamiento de ecosistemas frente a la introducción de OMGs solamente puede llegar a entenderse mediante su aplicación en el mundo real, infinitamente más complejo que el espacio confinado que ofrece un laboratorio ${ }^{55}$. Asimismo, conviene tener presente que ausencia de evidencia no es evidencia de ausencia de riesgo ${ }^{56}$.

\section{El riesgo en el Derecho de la UE}

Ni la Directiva 2001/18/CE ni el Reglamento (CE) 1829/2003 contienen una definición de riesgos. Sí lo hace el Reglamento (CE) 178/2002 que contiene la siguiente definición: "la ponderación de la probabilidad de un efecto perjudicial para la salud humana y la gravedad de ese efecto, como consecuencia de un factor de peligro" 57 .

Si bien esta definición se da en el contexto de la seguridad alimentaria, debe entenderse que su aplicación se hace extensiva a cuestiones medioambientales, toda vez que la legislación comunitaria de estas materias se encuentra estrechamente vinculada. Así, el mismo Reglamento 178/2002 indica en su

\footnotetext{
53 RODRÍGUEZ ZABALETA, H. "Riesgo y principio de precaución. Hacia una cultura de la incertidumbre". Revista Catalana de Seguretat Pública, 2003, № 13, p. 139.

54 HERRERA IZAGUIRRE, J. A. "El principio precautorio en la era de los OMG: incertidumbre y conflicto internacional". Medio Ambiente y Derecho, Revista electrónica de Derecho Ambiental, 2005, № 12-13. Disponible en: https://bit.ly/2FGhSMy [Última consulta, 9 de septiembre, 2018]. ${ }^{55}$ RODRÍGUEZ ZABALETA, H. "Riesgo y principio de precaución...", cit. p. 155.

56 TRAAVIK, T. Citado por BERGEL, S. "Enciclopedia de Bioderecho y Biotética...", cit. p. 1298.

${ }^{57}$ Artículo 3 número 9).
} 
artículo $1^{\circ}$ que su objetivo es asegurar "un nivel elevado de protección a la vida y la salud de las personas, de la sanidad y bienestar de los animales, del medio ambiente y de los intereses de los consumidores en relación con los alimentos y piensos modificados genéticamente" 58 .

Con todo, la interpretación de este concepto se torna más compleja cuando se aborda la ponderación o caracterización del riesgo, puesto que las normas analizadas establecen una serie de distinciones, tales como: riesgos posibles/potenciales, emergentes, graves, directos o indirectos, inmediatos 0 diferidos y cualquier riesgo, que es lo mismo que decir todo tipo de riesgo ${ }^{59}$. Respecto de los riesgos moderados, no existe una referencia expresa a ellos, pero del contenido de las diferentes disposiciones se deduce su consideración jurídica. Algunos ejemplos de estas calificaciones son:

a)

Posibles o potenciales: "Los Estados miembros y la Comisión deben garantizar que se lleve a cabo una investigación sistemática e independiente sobre los riesgos posibles..." 60 , "...los posibles efectos de dichos OMG sobre el medio ambiente..." 61, "Transferencia potencial de genes e impacto potencial en el medio ambiente inmediato $\mathrm{y} / \mathrm{o}$ diferido, posibles efectos inmediatos $\mathrm{y} / \mathrm{o}$ diferidos sobre la salud humana, posibles efectos inmediatos y/o diferidos para la salud animal"62, "...efectos potenciales sobre la inocuidad general de los alimentos..."63, “...información relativa a riesgos potenciales..."64.

b) Emergentes: “...la identificación de los riesgos emergentes puede convertirse a largo plazo en un instrumento preventivo...", "emprenderá

\footnotetext{
58 Del mismo modo, este Reglamento parte señalando en su primer Considerando del preámbulo que: "La libre circulación de alimentos seguros y saludables es un aspecto esencial del mercado interior y contribuye significativamente a la salud y el bienestar de los ciudadanos, así como a sus intereses sociales y económicos".

${ }^{59}$ La EFSA define caracterización del riesgo como "la etapa final de la evaluación de riesgos, en la cual la probabilidad de que una sustancia en particular cause daño se calcula a la luz de la naturaleza del peligro y la medida en que las personas, animales, plantas y/o el medio ambiente están expuestos a ella". Vid. Glosario de términos en: <https://bit.ly/2wYKI5Y> [Última consulta, 12 de septiembre de 2018].

60 Considerando 21 de la Directiva 2001/18

${ }^{61}$ Artículo 31, apartado 3, letra b) de la Directiva 2001/18

62 Apartado D, subapartado D1, números 4, 5, 6 y 7 del Anexo II de la Directiva 2001/18.

63 Considerando 14 del Reglamento (CE) 178/2002

${ }^{64}$ Artículo 27.4 del Reglamento (CE) 178/2002
} 
acciones para identificar y caracterizar los riesgos emergentes...", 65 "Cuando tenga información que le lleve a sospechar de un riesgo emergente grave...", 66 "La Autoridad transmitirá la evaluación y la información que recopile sobre riesgos emergentes..."67

c) Graves: "Deben buscarse los medios que faciliten el control de OMG o su retirada en caso de riesgos graves", 68 "...ppueden constituir un riesgo grave para la salud humana, la sanidad animal o el medio ambiente...", ${ }^{69}$ "Cuando un miembro de la red posea información relativa a la existencia de un riesgo grave, directo o indirecto..."70, “...constituya un riesgo grave para la salud de las personas, de los animales o para el medio ambiente...".71

d) Cualquier riesgo: “...el notificador enviará a la autoridad competente el resultado de la liberación con respecto a cualquier riesgo para la salud humana 0 el medio ambiente..., 72 “...la comercialización en la Comunidad de alimentos y piensos modificados genéticamente sólo debe autorizarse tras haberse llevado a cabo, bajo responsabilidad de la Autoridad, una evaluación del mayor nivel posible, de cualquier riesgo que presenten para la salud humana y la sanidad animal..."73.

En el año 2000, la CE emitió su Comunicación sobre el recurso al principio de precaución, que parte reconociendo que los responsables políticos se enfrentan al dilema de encontrar un equilibrio entre los intereses económicos y la necesidad de reducir los riesgos para el medio ambiente, la salud humana, animal y vegetal, sobre el que puedan adoptarse medidas proporcionadas, no discriminatorias, transparentes y coherentes. Así, "los responsables deben juzgar cuál es el nivel de riesgo «aceptable» para la sociedad". ${ }^{74}$

A fin de poder evaluar la pertinencia de la taxonomía del riesgo que se plantea por el legislador comunitario, se procederá en otro apartado a analizar la

\footnotetext{
${ }^{65}$ Artículo 23 letra f) del Reglamento (CE) 178/2002.

66 Artículo 34.2 del Reglamento (CE) 178/2002.

${ }^{67}$ Artículo 34.4 del Reglamento (CE) 178/2002.

68 Considerando 45 de la Directiva 2001/18.

${ }^{69}$ Artículo 34 del Reglamento 1829/2003.

70 Artículo 50.2 del Reglamento 178/2002.

${ }^{71}$ Artículo 53.1 del Reglamento 178/2002

72 Artículo 10 de la Directiva 2001/18.

${ }^{73}$ Considerando 9 del Reglamento (CE) 1829/2003.

74 Comunicación de la Comisión sobre el recurso al principio de precaución, cit.
} 
evidencia científica existente referente a los distintos riesgos que derivan del cultivo y consumo de los OMGs.

\section{El análisis de riesgos de los OMGs y sus etapas}

En la actualidad, este procedimiento se encuentra principalmente regulado en la Directiva 2001/18/CE, la que detalla los elementos científicos y las principales estrategias aplicables a la evaluación de riesgos. En este régimen complejo, se especifican obligaciones y diferentes medidas atendiendo a dos factores: por una parte, a la naturaleza del OMG que se trate y, por otra, a las características y fines de la operación que en concreta deba llevarse a cabo ${ }^{75}$. Posteriormente, el Reglamento 1829/2003 introdujo algunas modificaciones en la Directiva respecto del procedimiento de evaluación del riesgo.

Por su parte, el Panel OMG de EFSA ha elaborado una serie de documentos orientativos sobre plantas, microorganismos y animales modificados genéticamente ${ }^{76}$.

La jurisprudencia Comunitaria distingue tres etapas del análisis de riesgos:

- La evaluación,

- La gestión,

- La comunicación

Las dos primeras etapas están dirigidas a garantizar una base científica lo más rigurosa posible y a su vez, otorgar una discrecionalidad a la autoridad responsable al momento de adoptar una decisión sobre el riesgo. Es decir, por una parte, se basa una decisión política en antecedentes científicos y por la otra, se garantiza la autonomía de la autoridad en relación con los resultados de la evaluación científica ${ }^{77}$.

A su vez, la evaluación de riesgos se subdivide en tres tareas: identificación de riesgos, estimación de riesgos y valoración de estos. Con la primera, se logra

\footnotetext{
${ }^{75}$ ESCAJEDO SAN EPIFANIO, L. "Principio de precaución y riesgos ambientales..." cit. p. 180. ${ }^{76}$ WAIGMANN, E; PAOLETTI, C; DAVIES, H; PERRY, J; KÄRENLAMPI, S; KUIPER, H. "Risk assessment of Genetically Modified Organisms (GMOs)". EFSA Journal, 2012; Vol. 10, №10, Special Issue 1008, p. 2.

77 DE SADELEER, N. "Le principe de précaution dans le monde". Fondapol, Jean Jaures Fondation, 2011, París, p. 12.
} 
identificar una sustancia o una actividad tecnológica como peligrosa para el medio ambiente o la salud humana; se trata aquí de identificar las posibles consecuencias resultantes. Posteriormente, se calcula la probabilidad de ocurrencia de ese riesgo y su dimensión; se busca aplicar métodos analíticos para estimar la probabilidad de cada consecuencia y su magnitud.

Finalmente, se pondera el riesgo, determinando si es aceptable o no; se establecen comparaciones con riesgos aceptados con anterioridad y se evalúan los costes y beneficios asociados al riesgo ${ }^{78}$. Como la eliminación absoluta de riesgos es muy improbable y por tanto está fuera del alcance, a lo que más se puede aspirar es a elegir entre unos y otros intentando minimizarlos y dilucidar qué tipo de riesgos pueden aceptarse y cuáles no ${ }^{79}$.

En la segunda etapa, convergen dos fenómenos: El primero, es la existencia de regulaciones apoyadas en la ciencia que resultan problemáticas debido a que se basan en herramientas tradicionales de evaluación de riesgos que, dadas las características de éstos tales como la impredecibilidad, irreversibilidad y globalidad, entre otros, son altamente cuestionadas. El segundo, es el rol de la ciudadanía en este cuestionamiento, debido a que está mejor educada y tiene mayor acceso a información, lo que le permite ser más crítica y exigente con sus gobernantes y con el uso que se hace del conocimiento científico. Aquí es donde los conceptos de gobernanza y riesgo quedan vinculados a través del principio de precaución, especialmente en el caso de desarrollos tecnológicos que llevan asociado un alto grado de incertidumbre científica y con posibles efectos irreversibles ${ }^{80}$.

Finalmente, la comunicación consiste en el intercambio de información y opiniones en relación con los factores de peligro, los riesgos y la percepción de estos durante el proceso de análisis entre los responsables de la gestión, los consumidores, empresas, la comunidad científica y otros actores. En este intercambio, se incluyen la explicación de los resultados de la determinación de

\footnotetext{
${ }^{78}$ RODRÍGUEZ ZABALETA, H. "Riesgo y principio de precaución..." cit. p. 142.

79 RODRÍGUEZ LÓPEZ, B. "El cuidado debido. Organismos genéticamente modificados y principio de precaución". Dilemata, 2013, №11, p. 77.

80 DI MASSO, M. "Gestión política del riesgo: reflexiones en torno a las regulaciones europea y catalana de OMG". Papers, Revista de Sociología, 2008, N. 요 89, p. 47.
} 
riesgos y la motivación de las decisiones relativas a su gestión ${ }^{81}$. Mediante sus discursos, los actores implicados se encargan de mostrar o destacar su gestión, a los posibles responsables o las medidas a adoptar. De este modo, los procesos de evaluación y gestión del riesgo se transforman en procesos comunicacionales entre los diferentes actores o comunidades participantes ${ }^{82}$.

\section{RIESGOS DERIVADOS DE LOS OMGS}

En la actualidad, los riesgos derivados del cultivo y consumo de OMGs se clasifican en dos grandes categorías: En primer lugar, se encuentran los impactos no deseados en la salud de los ecosistemas, entre los que se consideran: la erosión genética, daños sobre especies no objetivo, el desarrollo de supermalezas, reducción de la eficiencia de pesticidas y herbicidas, modificación química y pérdida de la calidad del suelo y del agua por el uso de agrotóxicos y la pérdida de biodiversidad por el incremento de cultivos OMGs. En segundo lugar, se hallan los riesgos potenciales que los OMGs utilizados como alimentos y piensos tienen para la salud humana y sanidad animal ${ }^{83}$.

Siguiendo esta clasificación, se analizarán a continuación las principales evidencias científicas sobre los riesgos derivados de los OMGs:

\section{Riesgos para la salud de los ecosistemas}

Estos riesgos, también llamados ecológicos, son aquellos que derivan de la interacción de los OMG con otros organismos convencionales. El primero de éstos es la denominada erosión genética, que ha sido definida como el proceso de pérdida de variabilidad genética, la que puede afectar tanto a especies animales terrestres o acuáticos, como a vegetales y a microorganismos. La

${ }^{81}$ BULBOA CORTÉS, M. "Breves comentarios al análisis de riesgos en la seguridad alimentaria". Ecosostenible, 2006, N.16, sección artículos, p. 4.

82 GONZALO IGLESIA, J.L. "La teoría de la comunicación de riesgo". Comunicació i risc: III Congrés Internacional Associació Espanyola d'investigació de la comunicació, 2012, p. 178.

83 TSATSAKIS, A. NAWAZ, M. TUTELYAN, V. GOLOKHVAST, K. KALANTZI, O. CHUNG, D. KANG, S. COLEMAN, M. TYSHKO, N. YANG, S. CHUNG, G. "Impact on the environment, ecosystem, diversity and Health from culturing and using GMO as feed and food". Food and Chemical Toxicology, 2017. p. 109. 
principal causa de erosión genética es la imposición de la uniformidad, tanto biológica como cultural ${ }^{84}$.

Una de las principales consecuencias de los cultivos de OMG es que intensifica el modelo de monocultivo reforzados a partir de la revolución verde y las políticas agrícolas neoliberales. El desplazamiento de las variedades de cultivo autóctonas y los sistemas de cultivo biodiversos, aumenta la vulnerabilidad ante plagas y enfermedades, agota el suelo, incrementa la dependencia de fertilizantes sintéticos y biocidas tales como pesticidas o herbicidas y acrecienta la probabilidad de pérdidas catastróficas de cosechas. Así entonces, el cultivo de OMGs es intrínsecamente incompatible con la biodiversidad necesaria para promover la producción de alimentos sostenible y ecológica ${ }^{85}$.

También existe un subconjunto denominado biodiversidad agrícola o agrobiodiversidad, que es fruto de una prolongada y continuada interrelación entre las personas y su medio ambiente. Por tanto, tiene una doble dimensión: una natural y otra social y difícilmente puede ser comprendida sin considerar las dinámicas entre ambas dimensiones y sus consecuencias, fenómeno que algunos autores han denominado coevolución ${ }^{86}$.

Otros riesgos asociados al cultivo de OMG son: la transferencia de genes desde los cultivos transgénicos a cultivos convencionales y el desarrollo de supermalezas resistentes a herbicidas o resistentes a los insectos. La primera posibilidad es que los mismos cultivos de OMG se conviertan en supermalezas. Un ejemplo típico es el de las semillas de algodón tolerantes a herbicidas que quedan en los campos de la temporada anterior, pueden germinar entre la cosecha posterior de trigo, para lo cual se requeriría de la aplicación de un herbicida mucho más potente ${ }^{87}$.

En efecto, hay especies cuyas semillas pueden permanecer en estado latente y germinar después de 10 años o más. Esto supone la contaminación de cualquier

${ }^{84}$ GONZÁLEZ GUTIÉRREZ, J. "Biodiversidad agrícola y erosión genética". En: Especies exóticas invasoras en Andalucía. Talleres provinciales 2004-2006, p. 161.

${ }^{85}$ GONZÁLEZ, C. Genetically Modified Organisms and Justice: The International Environmental Justice Implications of Biotechnology". Georgetown International Environmental Law Review, 2007, Vol. 19, № 4, p. 23.

86 NORGAARD, R; SIKOR, T. "Metodología y práctica de la agroecología", en Miguel Altieri (Dir.), Agroecología. Bases científicas para una agricultura sustentable, capítulo II. CLADES/ACAO, La Habana, 1997, p. 34.

87 GONZÁLEZ, C. "Genetically Modified Organisms and Justice..." cit. p. 19. 
cultivo distinto que el inicial, ya sea de otra especie u otra variedad de la especie inicial. Esto ha sucedido, por ejemplo, con semillas de colza modificada genéticamente, que ha germinado en tierras sembradas con variedades convencionales y ha contaminado la cosecha ${ }^{88}$.

Para los defensores de los cultivos resistentes a herbicidas, esta tecnología constituye una herramienta que permite a los agricultores simplificar las tareas de control de malezas, al reducir el uso de estos químicos a situaciones de postemergencia, usando un sólo herbicida de amplio espectro que se descompone con relativa rapidez en el suelo. Sin embargo, se ha constatado que cuando se utiliza sólo un herbicida reiteradamente sobre un determinado cultivo, aumentan considerablemente las posibilidades de que la población de malezas desarrolle resistencia a éste ${ }^{89}$.

Este riesgo de transferencia se intensifica para las variedades silvestres que crecen próximas a los cultivos de OMG. De hecho, existe consenso científico en que los cultivos de OMG pueden con el tiempo transferir sus genes modificados a parientes silvestres. ${ }^{90}$

Un cuarto riesgo derivado de estos cultivos es la aceleración de resistencia a los herbicidas y pesticidas, pese a que por parte de los promotores se ha afirmado que la biotecnología agraria de los OMGs beneficiaría al medioambiente reduciendo el uso de herbicidas y pesticidas, existen estudios científicos que demuestran lo contrario.

Un estudio realizado por la organización Friends of the Earth International (FOEI) publicado en $2007^{91}$, concluyó que los cultivos de OMGs en los Estados Unidos han dado lugar a un significativo aumento en el uso de agroquímicos y una de las principales razones fue la evolución de la resistencia a los herbicidas de las malezas, lo que obligó a los agricultores a aplicar productos cada vez más

\footnotetext{
88 Vid. ECOLOGISTAS EN ACCIÓN. "Petición de dictamen al Defensor del Pueblo sobre: a) la imposibilidad de garantizar la futura alimentación y agricultura libre de OMG, b) en su caso, las reformas legales necesarias para ampararlas". Enero de 2010. Recurso electrónico disponible en: < http://bit.ly/1StWVC5> [Última consulta, 11 de abril de 2018].

${ }^{89}$ ALTIERI, M; NICHOLLS, C. "Agroecología. Teoría y práctica para una agricultura sustentable". Primera Edición, PNUMA, México DF, 2000, p. 138.

90 GONZÁLEZ, C. "Genetically Modified Organisms and Justice..." cit. p. 24.

${ }^{91}$ FRIENDS OF THE EARTH INTERNATIONAL (FOEI). "Who benefits from GM crops? An analysis of the global performance of GM crops (1996-2006), Amsterdam, 2007, p. 6.
} 
tóxicos. Los autores de este estudio sugirieron que el considerable aumento en el número de malezas resistentes al RoundUp de Monsanto es consecuencia directa del mayor y más frecuente uso de este herbicida asociado a los cultivos de soja, algodón y maíz, todos resistentes al RoundUp. Por tanto, lejos de haberse reducido el uso de agroquímicos debido al uso de semillas resistentes al herbicida, ha contribuido al aumento del uso en cantidad y toxicidad de estas sustancias $^{92}$.

Estos resultados se han visto corroborados por una investigación realizada por el Centre of Sustaining Agriculture and Natural Resources de la Universidad Estatal de Washington, que determinó que entre los años 1996-2011 se experimentó una propagación de malezas resistentes a herbicidas, lo que derivó en un aumento sustancial de la cantidad de herbicidas aplicados ${ }^{93}$.

Lo mismo podría suceder con algunos insectos debido al uso generalizado de variedades con el gen de resistencia Bt (Bacillus thuringiensis), lo que llevaría a acelerar el desarrollo de la resistencia a este pesticida, lo que derivaría en el uso de mayores cantidades de pesticidas cada vez más tóxicos ${ }^{94}$. El desarrollo de la resistencia al Bt por parte de los insectos no solo perjudicaría a los agricultores que cultivan estas variedades, sino también a los vecinos que aplican $\mathrm{Bt}$ microbiana como un insecticida natural en los cultivos convencionales ${ }^{95}$.

En el caso de España, al parecer esta estrategia no ha dado los resultados esperados, toda vez que la producción de la toxina Bt es muy variable en distintos cultivos, así como en un mismo cultivo; es decir, depende de cada planta ${ }^{96}$.

\footnotetext{
92 GONZÁLEZ, C. "Genetically Modified Organisms and Justice..." cit. p. 21.

${ }^{93}$ BENBROOK, Ch. "Impacts of genetically engineered crops on pesticide use in the U.S. - the first sixteen years". Environmental Sciences Europe 2012, Vol. 24 №24, p. 12.

94 Por otra parte, un estudio realizado en Argentina del año 2014 concluyó que quinientas cincuenta especies distintas de artrópodos plaga pueden desarrollar a través de un proceso microevolutivo, la capacidad para tolerar las restricciones biológicas que impone la tecnología Bt. Sin duda, esta resistencia constituye una amenaza para la salud pública y la agricultura a nivel mundial TRUMPER, E. "Resistencia de insectos a cultivos transgénicos con propiedades insecticidas. Teoría, estado del arte y desafíos para la República Argentina". Agriscientia, 2014, Vol. 31, № 2, p. 110.

95 GONZÁLEZ, C. "Genetically Modified Organisms and Justice..." cit. p. 24.

96 FOEI, COAG, ECOLOGISTAS EN ACCIÓN, GREENPEACE y CECU. ."Implicaciones socioeconómicas de la introducción de OMGs en el mercado para su cultivo". Marzo de 2009. Recurso electrónico, disponible en: <http://bit.ly/1OFxFaW> [Última consulta,13 de septiembre de 2018]. cit. p. 35.
} 
Finalmente, se encentran los daños provocados a organismos no objetivo. Es decir, los cultivos OMGs pueden dañar a otros organismos beneficiosos, como aquellos que viven en el suelo y aquellos depredadores naturales de las plagas de insectos, lo que también va en directo perjuicio de aquellos agricultores que no quieren o no pueden permitirse el uso de pesticidas ya que, al desaparecer los depredadores naturales, sus cultivos quedan expuestos. Lo mismo ocurre con la desaparición de la biota, puesto que estos agricultores no utilizan fertilizantes químicos. También se ha detectado contaminación por herbicidas en aguas y patologías derivadas en peces ${ }^{97}$.

En consecuencia, es probable que el uso de pesticidas y de agroquímicos sirva para controlar plagas y para reponer la fertilidad del suelo, pero sin duda conlleva importantes daños para el medio ambiente y la salud humana y animal, además de las implicaciones socioeconómicas antes indicadas ${ }^{98}$.

Un caso estudiado en Estados Unidos en el año 1999 fue el de las larvas de la Mariposa Monarca (Danaus plexippus) las cuales experimentaron un crecimiento más lento y una altísima mortalidad, debido a que el polen de una variedad de maíz Bt se dispersaba por acción del viento en un perímetro de 60 metros, por lo que el polen que contenía la toxina Bt se depositó sobre las hojas del algodoncillo ${ }^{99}$. Pese a lo antes señalado, parte de la comunidad científica considera muy ventajosa la tecnología Bt, puesto que aparentemente no tendría efectos sobre vertebrados y seres humanos o el entorno ecológico; un bajo impacto en organismos no objetivo y que no afectaría a las hojas, principal alimento de los lepidópteros (mariposas), entre otras ventajas ${ }^{100}$.

\footnotetext{
97 Otro caso documentado es el de peces de la especie Poecilia Reticulata "rebistes", que han evidenciado toxicidad aguda (mortalidad) y toxicidad crónica debido a la contaminación de las aguas con dos herbicidas comerciales formulados a base de glifosato, utilizados en los monocultivos de soja transgénica en Argentina. La formulación RoundUp, que la utilizada para los monocultivos y por tanto de forma extensiva, resultó ser la más tóxica. ÁLVAREZ, M; GIMÉNEZ, I; SAITUA, H; ENRIZ, R; GIANNINI, F. "Toxicidad en peces de herbicidas formulados con glifosato". Acta toxicológica argentina, 2012, Vol. 20 N. ${ }^{\circ} 1$, p. 12.

98 GONZÁLEZ, C. "Genetically Modified Organisms and Justice..." cit. p. 25.

99 LOSEY, J; RAYOR, L; CARTER, M. "Transgenic pollen harms monarch larvae". Nature, 1999, Vol. 399, p. 214.

${ }^{100} \mathrm{ROH}, \mathrm{J} ; \mathrm{CHOI}, \mathrm{J} ; \mathrm{LI}, \mathrm{M}$; JIN, B; JE, Y. "Bacillus thuringiensis as a specific, safe, and effective tool for insect pest control”. Journal Of Microbiology And Biotechnology. 2007, Vol. 17, № 4, p. 548.
} 


\section{Riesgos para la salud humana y animal}

El uso de tecnología de ADN recombinante en el sector alimenticio ha planteado una serie de cuestionamientos sobre su seguridad. Esto abarca tanto a los OMGs en sí mismos, como los que contienen un ingrediente derivado de un OMG y también aquellos alimentos que han sido producidos con la utilización de enzimas $u$ otros productos auxiliares en el procesamiento ${ }^{101}$. Lo mismo ocurre para el caso de piensos de animales destinados al consumo humano.

En primer lugar, se alude a un desmejoramiento de la nutrición por la reducción del consumo de alimentos variados. Los defensores de los OMGs ponen como ejemplo de los beneficios de esta tecnología al arroz dorado transgénico que produce beta-caroteno, sustancia que el cuerpo puede convertir en vitamina A. Sin embargo, los críticos han planteado varias inquietudes en el contexto del arroz dorado que son relevantes para todas las variedades de OMG diseñados para mejorar la calidad nutricional.

Ante todo, no queda claro si los individuos desnutridos tienen la grasa suficiente para poder metabolizar el beta-caroteno del arroz dorado; a su vez, el color amarillo del arroz produjo que, por razones culturales, fuera rechazado por ciertos grupos y, lo más importante, la deficiencia de vitamina $A$ se debe a la disminución de cultivos y a la pérdida de diversidad alimentaria. Por tanto, en vez de alterar genéticamente una variedad de arroz, sería más efectivo abordar el problema de fondo a través de la introducción de múltiples cultivos ${ }^{102}$.

Al igual que otras variedades de arroz utilizadas durante la revolución verde, el arroz dorado es producido mediante técnicas de monocultivo, por tanto requiere de fertilizantes, pesticidas y regadío intenso, produciendo por tanto alteraciones en los ciclos de nitrógeno y fósforo y escasez de agua ${ }^{103}$.

Un segundo riesgo descrito por la ciencia es el aumento de la transmisión de enfermedades infecciosas debido a la pérdida de biodiversidad. Un informe realizado en 2015 por el Programa para el Medio Ambiente de la ONU (UNEP

${ }^{101}$ ALMODÓVAR IÑESTA, M. "Aspectos jurídicos de la biotecnología agroalimentaria". Revista interdisciplinar de Gestión Ambiental, 2001, año 3, № 28, versión electrónica de La Página del Medio Ambiente.

102 GONZÁLEZ, C. "Genetically Modified Organisms and Justice..." cit. p. 22.

103 STONE, G. y GLOVER, D. "Disembedding grain: Golden Rice, the green revolution, and heirloom seeds in the Philippines". Agriculture and Human Values, 2016, Vol. 34, Issue 1, p. 88. 
por sus siglas en inglés), la Secretaría del Convenio sobre la Diversidad Biológica (CDB) y la Organización Mundial de la Salud (OMS) titulado "Connecting Global Priorities: Biodiversity and Human Health. A State of Knowledge Review", que concluye que la pérdida de biodiversidad incide en el incremento de transmisiones de enfermedades infecciosas, como por ejemplo la enfermedad de Chagas, ya que las vinchucas (el insecto que lo transmite) crecen más y mejor cuando la vegetación nativa es reemplazada por cultivos comerciales; en la región amazónica aumentaron nueve veces las mordidas de murciélagos, consecuencia directa de la deforestación y en Estados de Brasil, como Pará, se multiplicó por cuarenta. Algo similar ocurre con el aumento del mosquito Anopheles que transmite la malaria y el hantavirus en el cono sur de América, transmitido por roedores ${ }^{104}$.

En tercer lugar, se denuncia la aparición de nuevas alergias por introducción de nuevas proteínas en los alimentos. En el año 1996, se publicó un estudio que causó gran revuelo debido a que se demostró que la empresa Pioneer Hi-Bred International había introducido en una variedad de soja modificada genéticamente (Glycinemax), la proteína albúmina $2 S$ rica en metionina proveniente de la nuez amazónica (Bertholletia excelsa) con el fin de mejorar la calidad nutricional de la primera. Dado que la nuez amazónica o semilla de Brasil es conocida por su alta alergenicidad, se evaluó la proteína albúmina 2S, la que dio un resultado positivo ${ }^{105}$.

Años más tarde, un Grupo Asesor Científico (SAP por sus siglas en inglés) entregó a la Agencia de Protección Ambiental de los Estados Unidos (EPA por sus siglas en inglés), un Informe sobre la capacidad alergénica potencial de la variedad de maíz Starlink en el cual concluyó que existía una probabilidad media de que la proteína del Starlink sea un potencial alérgeno para los seres humanos ${ }^{106}$.

\footnotetext{
104 UNEP, CDB, OMS, Connecting Global Priorities: Biodiversity and Human Health. A State of Knowledge Review. OMS Library, Ginebra, 2015, p. 137.

${ }^{105}$ NORDLEE, J. TAYLOR, S. TOWNSEND, J. THOMAS, L. BUSH, R. "Identification of a BrazilNut allergen in transgenic soybeans". The New England Journal of Medicine, 14 de marzo de 1996, Vol. 334, № 11, p. 688.

106 Vid. Informe del SAP y las recomendaciones de la EPA en el siguiente enlace: <http://1.usa.gov/1IFLAsS> [Última consulta, 8 de septiembre de 2018].
} 
En las pruebas de digestión artificial realizadas, la proteína Cry9C había tardado más que la Cry $1 \mathrm{~A}$ en descomponerse y por ello despertó las sospechas de los inspectores de la Environmental Protection Agency de los Estados Unidos (EPA) ya que además presentaba otras características de los alérgenos. Como finalmente no se resolvió la cuestión en relación con la proteína Cry9C, la EPA otorgó el permiso para producir el maíz siempre y cuando no fuera destinado al consumo humano.

Otro de los riesgos preocupantes hasta ahora estudiados, es la aparición de resistencias a antibióticos en bacterias patógenas para el ser humano, como consecuencia de la utilización en el proceso de recombinación de ADN genes marcadores con resistencia a ciertos antibióticos. La cuestión radica en que esa resistencia llegue a las bacterias del organismo humano, lo que generaría una resistencia a los antibióticos que pondría en riesgo la salud pública. ${ }^{107}$

Los suelos agrícolas son plataformas versátiles de intercambio de genes, proporcionando la matriz física para cerrar el ciclo de la transferencia bidireccional de genes de resistencia a antibióticos entre humano-animalessuelo y bacterias asociadas a las plantas. La aplicación de estiércol, fangos cloacales o aguas residuales vertidos sobre los campos, actúan como conductores para la transferencia de genes resistentes y el intercambio de patógenos.

En el caso de los desechos humanos, están generalmente contaminados con agentes antimicrobianos procedentes de tratamientos con antibióticos. Estos antibióticos de origen antropogénico que aparecen en concentraciones mayores a las normalmente encontradas en el suelo son considerados contaminantes. Asimismo, las bacterias resistentes a los antibióticos pueden considerarse como contaminantes del medio ambiente si contienen genes de resistencia a antibióticos y se introducen en ecosistemas no expuestos, por la actividad humana ${ }^{108}$.

\footnotetext{
107 ALMODÓVAR IÑESTA, M. "Aspectos jurídicos..." cit.

$108 \mathrm{Tal}$ es el caso de los genes aminoglucósido fosfotransferasa nptll y nptlll, que son los más usados como marcadores de resistencia a antibióticos en plantas transgénicas. El gen nptll inactiva la kanamicina y la neomicina, ambos recientemente clasificados como de fundamental importancia para los seres humanos y animales. Por su parte, el gen nptlll inactiva la amikacina que es un antimicrobiano crucial para el tratamiento de infecciones graves en humanos. WOEGERBAUER, M; ZEINZINGER, J; GOTTSBERGER, R; PASCHER, K; HUFNAGL, P;
} 
Finalmente, las investigaciones más polémicas y con mayor impacto, dicen relación con la aparición de posibles patologías en animales y seres humanos. En el año 1999, se publicó en la revista The Lancet, un estudio encabezado por Arpad Pusztai, titulado "Effect of diets containing genetically modified potatoes expressing" en el cual se concluía que en los experimentos realizados se habrían evidenciado efectos nocivos en la salud de las ratas que fueron alimentadas con variedades de patatas transgénicas.

El impacto de este estudio se intensificó luego que Pusztai hiciera algunas declaraciones en televisión antes de publicar su investigación, en las cuales llegó incluso a afirmar que los ciudadanos estaban siendo utilizados como meras cobayas por las empresas involucradas y los gobiernos permisivos ${ }^{109}$.

La reacción de la comunidad científica y las empresas biotecnológicas no se hizo esperar: The Royal Society of Medicine del Reino Unido encomendó la realización de un nuevo estudio por un grupo de expertos supuestamente imparciales e independientes. En este estudio, se acusó la existencia de algunos problemas de diseño, ejecución y análisis experimental que le restaban validez a los resultados informados por el grupo de Pusztai. Pero lo que más criticó The Royal Society fue la forma en que se difundieron las conclusiones. Además, Pusztai fue destituido de su cargo en el Rowett Research Institute ${ }^{110 .}$

Por otro lado, los descubrimientos de Pusztai y su equipo fueron avalados por un grupo de 20 científicos de todo el mundo, quienes estuvieron de acuerdo en sus conclusiones tras analizar los datos y resultados. Este grupo de científicos emitió un documento mediante el cual instaron a las autoridades a aumentar la financiación para continuar las investigaciones sobre la materia y exigieron la inmediata restitución de Puzstai a su cargo ${ }^{111}$.

INDRA, A; FUCHS, R; HOFRICHTER, J; KOPACKA, I; KORSCHINECK, I; SCHEILER, C; SCHWARZ, M; STEINWIDER, J; SPRINGER, B; ALLERBERGER, F; NIELSEN, K; FUCHS, K. "Antibiotic resistance marker genes as environmental pollutants in GMO-pristine agricultural soils in Austria". Environmental Pollution, 2015, N. ${ }^{\circ} 206$, p. 350.

${ }^{109}$ ROBIN, M. "El Mundo según Monsanto: de la dioxina a los OMG: una multinacional que les desea lo mejor". Editorial Península, Barcelona, 2008, p. 275.

110 LARRIÓN CARTUJO, J. "La resistencia a las razones de Pusztai. El conocimiento y la incertidumbre en la polémica sobre los organismos modificados genéticamente". Política y Sociedad, 2010, Vol. 47, №1, p. 219.

111 YOKE HEONG, C. "Alimentos transgénicos y bioseguridad. Descubrimientos científicos siembran alarma". Revista del Sur, junio de 1999, № 92. 
En los años posteriores, se realizaron múltiples investigaciones acerca de los daños causados por el glifosato, los cuales establecieron que este herbicida altera el ciclo celular y los mecanismos de reparación del $A D N^{112}$, induce la apoptosis o muerte celular ${ }^{113}$, penetra la barrera placentaria ${ }^{114}$ e induce genotoxicidad ${ }^{115}$; se han observado malformaciones producidas por el glifosato en ranas Xenopus, pollos y también en mamíferos ${ }^{116}$. En Paraguay, se ha detectado un aumento de malformaciones en humanos, sobre todo en zonas aledañas a zonas donde se produce la soja transgénica y se realiza un uso intensivo de este herbicida ${ }^{117}$.

El debate en Europa respecto de la seguridad de los OMG se vio reavivado el año 2012 con la publicación del estudio Long term toxicity of a Round Up herbicide and a Round Up-tolerant genetically modified maize, realizado por un grupo de investigadores franceses encabezados por Gilles-Eric Séralini, el cual consistió en alimentar a distintos grupos de ratas de ambos sexos con maíz transgénico NK603, maíz NK603 más RoundUp y otro con herbicida RoundUp ${ }^{118}$.

En cuanto al herbicida RoundUp, en experimentos anteriores sólo se había evaluado su principio activo, el Glifosato, mientras que en esta ocasión se utilizó la fórmula completa, es decir, el herbicida en la forma que se comercializa. La

\footnotetext{
112 MARC, J; MULNER-LORILLON, O; BOULBEN, S; HUREAU, D; DURAND, G; BELLÉ, R. "Pesticide Roundup provokes cell division dysfunction at the level of CDK1/cyclin B activation". Chemical Research in Toxicology. 2002; Vol. 15, № 3, p. 331.

${ }^{113}$ BENACHOUR, N; SÈRALINI, G.E. "Glyphosate formulations induce apoptosis and necrosis in human umbilical, embryonic, and placental cells". Chemical Research in Toxicology. 2009, Vol. 22, № 1, p.105.

114 POULSEN, M.S; RYTTING, E; MOSE, T; KNUDSEN, L.E. "Modeling placental transport: correlation of in vitro BeWo cell permeability and ex vivo human placental perfusión". Toxicology in vitro, 2009, Vol. 23, № 7, p.1386.

115 MAÑAS, F; PERALTA, L; RAVIOLO, J; GARCÍA, O.H; WEYERS, A; UGNIA, L; GONZÁLEZ, C.M; LARRIPA, I; GORLA, N. "Genotoxicity of glyphosate assessed by the comet assay and cytogenetic tests". Environmental Toxicology and Pharmacology. 2009, Vol. 28, No 1, p. 41.

116 DALLEGRAVE, E; MANTESE, F.D; COELHO, R.S; PEREIRA, J.D; DALSENTER, P; LANGELOH, A. "The teratogenic potential of the herbicide glyphosate-Roundup in Wistar rats". Toxicology Letters, 2003, Vol. 142, №12, p. 52.

117 CARRASCO, A. "Glyphosate: part of eugenics model?". Salud colectiva, 2011, Vol. 7, № 2, p.129.

118 SÉRALINI, G. CLAIR E. MESNAGE R. GRESS S. DEFARGE N. MALATESTA, M. HENNEQUIN D. SPIROUX DE VENDOMOIS, J. "Long term toxicity of a Roundup herbicide and a Roundup-tolerant genetically modified maize". Food and Chemical Toxicology, 2012, Vol. 50, Issue 11, p. 4230.
} 
razón de ello es que la fórmula incluye coadyuvantes que podrían resultar más nocivos para las ratas que el principio activo.

Tras la publicación del estudio, EFSA emitió de forma inmediata un informe en el que ponía de manifiesto la existencia de lagunas en el estudio, razón por la cual lo calificaba de no concluyente ${ }^{119}$. Asimismo, se le pidió a Séralini que contestara a las observaciones formuladas, puesto que este organismo consideró que las conclusiones del estudio no podían ser estimadas como válidas científicamente ya que ni el diseño del informe ni el análisis de los datos eran suficientes, por tanto, no veía necesario volver a evaluar la seguridad del maíz NK603 ${ }^{120}$.

El Editor Jefe reconoció en su carta que los evaluadores anónimos no encontraron nada incorrecto sobre los resultados presentados, sino más bien se apunta a la naturaleza inconclusa de algunos aspectos del artículo para justificar la retractación.

Pero a diferencia del caso del estudio de Pusztai, el conflicto no quedó allí. Hubo una gran movilización por parte de la comunidad científica europea e internacional y de la opinión pública a favor del grupo encabezado por Séralini, el cual llevó a que el artículo fuera republicado por la Revista Environmental Science Europe bajo el título "Republished study: long-term toxicity of a Roundup herbicide and a Roundup-tolerant genetically modified maize". Esta versión contiene material adicional que acalla las críticas hechas a la publicación original. Además, la republicación viene acompañada de un comentario a parte del equipo del Sr. Séralini en el cual se describen los esfuerzos del lobby de parte de grupos pro-OMG y describen cómo se forzó al Editor de la primera revista para que retire la primera versión ${ }^{121}$.

\footnotetext{
119 EUROPEAN FOOD SAFETY AUTHORITY: "Review of the Seralini et al. (2012) publication on a 2-year rodent feeding study glyphosate formulations and GM maize NK603 as published online on 19 September 2012 in Food and Chemical Toxicology." EFSA Journal, 2013, Vol. 10, Issue 10, p. 9.

120 BACHMANN FUENTES, R.I. "Normas de seguridad alimentaria de la Unión Europea. Presumiendo la inocuidad de los organismos modificados genéticamente". Actualidad Jurídica Ambiental, enero 2013, № 1, p. 12.

121 Vid. GMOSERALINI. "Republicación del estudio de Séralini: la ciencia habla por sí misma". Recurso electrónico, publicado el 24 de junio de 2014, disponible en: <http://bit.ly/1ruVJ47> [Última consulta, 11 de abril de 2018].
} 
En definitiva, esta investigación científica revisada por pares afirmó que el maíz NK603 y el pesticida RoundUp causan daños hepáticos y renales crónicos con un potencial y significativo riesgo para la salud humana y animal ${ }^{122}$, demostrando la toxicidad del glifosato y que las formulaciones son tóxicas en niveles muy inferiores a los umbrales regulados para este agrotóxico ${ }^{123}$.

\section{CONCLUSIONES}

Puede apreciarse que el Derecho de la bioseguridad fue evolucionando desde una posición muy restrictiva hacia una cada vez más permisiva y que, por el contrario, existe una importante cantidad de evidencia científica independiente que fue confirmando los temores que desde un principio se habían pronosticado, en cuanto a la existencia de múltiples daños ambientales y sanitarios de gran impacto, los que demandan una mayor intervención jurídica como, asimismo, mayor rigurosidad en el análisis de riesgos. Es decir, se podría estar produciendo una dicotomía entre las normas reguladoras y el conocimiento científico; una bifurcación que podría terminar por disociar el Derecho de la realidad que pretende regular.

Esta disociación entre las normas y el avance científico quedaría latente en el hecho de que las primeras distinguen entre distintos tipos de riesgos según su magnitud y alcance, mientras que los diagnósticos realizados por los distintos estudios científicos sólo distinguen entre daños a mediano y largo plazo, pero en ningún caso de riesgos leves y graves, ya que, como antes se indicó, todos los riesgos analizados -en el caso de no ser controlados oportunamente- pueden ocasionar daños importantes e irreversibles. Por tanto, convendría incorporar en el debate jurídico sobre el riesgo el elemento temporal, es decir, la distinción entre riesgos de mediano y largo plazo lo que, sin lugar a duda, otorga mayor relevancia al elemento incertidumbre.

122 Como consecuencia de esta polémica, se procedió en Francia a dictar la LOI $n^{\circ} 2014-567 d u$ 2 juin 2014 relative à l'interdiction de la mise en culture des variétés de maïs génétiquement modifié

123 FAGAN, J. TRAAVIK, T. BOHN, T. "The Seralini affair: degeneration of Science to ReScience? Environmental Science Europe, 2015, Vol. 27, № 19, p. 3. 
En segundo lugar, plantea un grave problema el hecho de que el TJUE restrinja la aplicación del principio de precaución a las medidas provisionales de gestión del riesgo de los OMGs, excluyendo su aplicación en las medidas de emergencia adoptadas en virtud del artículo 34 del Reglamento № 1829/2003, ya que como aquí se ha expuesto, el principio de cautela se encuentra consagrado en el Derecho originario de la UE como principio general del Derecho comunitario. Por tanto, debe entenderse aplicable a todas y cada una de las normas que se refieran a la prevención y gestión de riesgos al medio ambiente, salud humana y sanidad animal.

Asimismo, podría entenderse que la existencia de incertidumbre científica incomoda tanto a los organismos científicos evaluadores como EFSA, a la CE y al TJUE, razón por la cual omiten referirse a esta circunstancia en sus decisiones. Así las cosas, los antecedentes científicos aportados por los Estados interesados siempre serán calificados de insuficientes y en consecuencia cualquier medida de emergencia que se quiera adoptar sería considerada como injustificada, puesto que la incertidumbre siempre estará presente, ya que es improbable de que haya consenso científico en torno a los riesgos, especialmente cuando convergen intereses comerciales y estén detrás las grandes compañías de la agroindustria.

De esta manera, se colige que la tecnociencia es -al mismo tiempo-fuente de soluciones y problemas, ya que los estudios aportados por los Estados y también los independientes, son refutados por dictámenes de EFSA, los que a su vez sirven de base para los informes de los Abogados Generales, de las resoluciones de la CE y del TJUE al momento de resolver sobre la aplicación de medidas de emergencia. Esto nos lleva a considerar la necesidad de que la evaluación científica de riesgos deba someterse a un proceso de redefinición, en el cual cobraría un interés preponderante el debate sobre cómo deben desarrollarse los resultados científico-tecnológicos y sobre el tipo de ciencia necesaria para hacer frente a los efectos negativos de su desarrollo ${ }^{124}$. Por supuesto, debe debatirse sobre qué riesgos está dispuesta a asumir la sociedad y sobre esta base, regular.

${ }^{124}$ DI MASSO, M. "Gestión política del riesgo: reflexiones en torno a..." cit. p. 49. 
Esta centralización y subjetividad de la opinión científica conlleva un serio riesgo para la ciudadanía, puesto que la sume en un estado de indefensión científica. Es decir, vulnera su derecho a una ciencia objetiva e independiente y, en consecuencia, a plantear la conveniencia de impulsar modelos de ordenanza medioambiental y tecnocientífica, puesto que la innegable influencia del sector agroindustrial hace más evidente la urgencia de garantizar los derechos de participación y acceso a la información en estas materias.

También se hace necesario que la UE en cooperación con los Estados miembros, respete la autonomía de los organismos evaluadores. Es decir, debería fortalecerse en conjunto el desarrollo de una ciencia objetiva, independiente y de alto nivel; ajena las presiones de la gran industria biotecnológica transnacional y el poder político. La industria financia muy bien a los científicos que informan favorablemente a sus pretensiones y ejercen una constante presión sobre el colectivo de investigadores independientes. Además, introduce obstáculos que pueden retrasar o desviar el desarrollo científico. A la larga, esto pone en peligro el interés público como, asimismo, los propios intereses de la industria biotecnológica ${ }^{125}$.

Finalmente, atendiendo a lo aquí expuesto, podría concluirse que la CE y el TJUE no estarían garantizando adecuadamente la protección del medio ambiente, la salud humana y sanidad animal, ya que tienden a desestimar evidencia científica nueva que justificaría la adopción de medidas de emergencia, priorizándose por tanto intereses de índole comercial. En el actual contexto de crisis ambiental global y continental, se exige a las autoridades un papel más activo en la prevención de riesgos medioambientales; el avance hacia una agricultura sostenible y por tanto una mayor visión de futuro, basada en modelos industriales inocuos y no contaminantes. Para ello, el Derecho y las instituciones que lo crean, interpretan y aplican, deben estar a la altura de las circunstancias.

\section{BIBLIOGRAFÍA}

${ }^{125}$ FAGAN, J. TRAAVIK, T. BOHN, T. "The Seralini affair: degeneration of Science ..." cit. p. 7. 
ALMODÓVAR IÑESTA, M. "Aspectos jurídicos de la biotecnología agroalimentaria". Revista interdisciplinar de Gestión Ambiental, 2001, año 3, № 28, versión electrónica de La Página del Medio Ambiente.

ÁlVAREZ, M. GIMÉNEZ, I. SAITUA, H. ENRIZ, R. GIANNINI, F. "Toxicidad en peces de herbicidas formulados con Glifosato". Acta toxicológica Argentina, 2012, Vol. 20, № 1, p. 5-13.

ALTIERI, M; NICHOLLS, C. "Agroecología. Teoría y práctica para una agricultura sustentable". Primera Edición, PNUMA, México DF, 2000, p. 1-239.

ANDORNO, R. "The Precautionary Principle: A New Legal Standard for a Technological Age". Journal of International Biotechnology Law, 2004, Vol. 1, № 1, p. 11-19.

BACHMANN FUENTES, I. "Normas de seguridad alimentaria de la Unión Europea. Presumiendo la inocuidad de los organismos modificados genéticamente". Actualidad Jurídica Ambiental, enero 2013, № 1, p. 1-22.

BECK, U. "La sociedad del riesgo. Hacia una nueva modernidad". Paidós Ibérica, Barcelona, 1986.

BENACHOUR, N; SĖRALINI, G.E. "Glyphosate formulations induce apoptosis and necrosis in human umbilical, embryonic, and placental cells". Chemical Research in Toxicology. 2009, Vol. 22, № 1, p. 97-105.

BENBROOK, Ch. "Impacts of genetically engineered crops on pesticide use in the U.S. - the first sixteen years". Environmental Sciences Europe 2012, Vol. 24 №24, p. 1-13.

BERBEROFF AYUDA, D. "Incertidumbre científica y riesgo: cinco ideas fuerza a propósito del principio de precaución", en El principio de precaución y su proyección en el Derecho administrativo español. Manuales de formación continuada 26, Consejo General del Poder Judicial, Madrid, 2005, p. 15-38.

BERGEL, S. "Precaución, principio de", en Enciclopedia de Bioderecho y Bioética, Cátedra Interuniversitaria Fundación BBVA-Diputación Foral de Bizkaia de Derecho y Genoma Humano, Universidad de Deusto y Universidad del País Vasco, Edit. Comares, Tomo II, Granada, 2011.

BUCHINNI, L; GOLDMAN, L. "Starlink Corn: A Risk Analysis". Environmental Health Perspectives, 2002, Vol. 110, № 1, p. 5-13.

BULBOA CORTÉS, M. "Breves comentarios al análisis de riesgos en la seguridad alimentaria". Ecosostenible, 2006, № 16, sección artículos, p. 3-9. 
CARRASCO, A. "Glyphosate: part of eugenics model?" Salud colectiva, 2011, Vol. 7, № 2, p.129-133.

CORTINA, A. "Fundamentos filosóficos del principio de precaución", en Carlos Romeo Casabona (Coord.), Principio de precaución, Biotecnología y Derecho. Cátedra Interuniversitaria Fundación BBVA-Diputación Foral de Bizkaia de Derecho y Genoma Humano, Edit. Comares, Granada, 2004, p. 3-16.

DALLEGRAVE, E; MANTESE, F.D; COELHO, R.S; PEREIRA, J.D; DALSENTER, P; LANGELOH, A. "The teratogenic potential of the herbicide glyphosate-Roundup in Wistar rats". Toxicology Letters, 2003, Vol. 142, № 12, p. 45-52.

DEMANĖCHE, S. SANGUIN, H. POTÉ, J. NAVARRO, E. BERNILLON, D. MAVINGUI, P. WILDI, W. VOGEL, T. SIMONET, P. "Antibiotic resistant soil bacteria in transgenic plant fields". PNAS, 2008, Vol. 105, № 10, p. 3957-3962.

DI MASSO TARDITTI, M. "Gestión política del riesgo: reflexiones en torno a las regulaciones europea y catalana de OMG". Papers, Revista de Sociología, 2008, № 89, p. 41-63

DURANT, J. BAUER, M. GASKELL, G. "Biotechnology in the Public Sphere: A European Sourcebook". NMSI Trading Ltd., Londres, 1998.

ECOLOGISTAS EN ACCIÓN. "Petición de dictamen al Defensor del Pueblo sobre: a) la imposibilidad de garantizar la futura alimentación y agricultura libre de OMG, b) en su caso, las reformas legales necesarias para ampararlas". Enero de 2010. Recurso electrónico, revisado el 11 de abril de 2018. Disponible en: $<$ http://bit.ly/1StWVC5>.

EUROPEAN FOOD SAFETY AUTHORITY. "Review of the Seralini et al. (2012) publication on a 2-year rodent feeding study glyphosate formulations and GM maize NK603 as published online on 19 September 2012 in Food and Chemical Toxicology." EFSA Journal, 2012, Vol. 10, Issue 10, p. 1-9.

EUROPEAN FOOD SAFETY AUTHORITY, "Scientific Opinion on a request from the European Commission related to a emergency measure notified by Italy on genetically modified maize MON810 according to Article 34 of Regulation (EC) № 1829/2003". EFSA Journal, 2013, Vol. 11, № 9, p. 1-21.

ESCAJEDO SAN EPIFANIO, L. "Principio de precaución y riesgos ambientales, especialmente los asociados a los OMG", en Carlos Romeo Casabona (Coord.), Principio de precaución, Biotecnología y Derecho. Cátedra Interuniversitaria 
Fundación BBVA-Diputación Foral de Bizkaia de Derecho y Genoma Humano, Edit. Comares, Granada, 2004, p. 149-218.

ESPLUGA, J. "Ulrich Beck i les dimensiones socials del risc". Medi ambient: Tecnología i cultura, № 24, 1999. Recurso electrónico disponible en: http://www.gencat.cat/mediamb/revista/rev24-4.htm> [Última consulta, 3 de septiembre de 2018].

ESTEVE PARDO, J. "La operatividad del principio de precaución en materia ambiental", en El principio de precaución y su proyección en el derecho administrativo español. Manuales de formación continuada 26, Consejo General del Poder Judicial, Madrid, 2005, p. 191-214.

EWEN, S; PUSZTAI, A. "Effect of diets containing genetically modified potatoes expressing Galanthus nivalis lectin on rat small intestine". The Lancet, 1999, Vol. 354, p.1353-1354.

FAGAN, J. TRAAVIK, T. BOHN, T. "The Seralini affair: degeneration of Science to Re-Science? Environmental Science Europe, 2015, Vol. 27, № 19, p. 1-9.

FOEI. "Who benefits from GM crops? An analysis of the global performance of GM crops (1996-2006), Amsterdam, 2007. Recurso electrónico disponible en: $<$ http://bit.ly/1N1grC1> [Última consulta, 14 de mayo de 2018].

FOEI, COAG, ECOLOGISTAS EN ACCIÓN, GREENPEACE y CECU."Implicaciones socio-económicas de la introducción de OMGs en el mercado para su cultivo". Marzo de 2009. Recurso electrónico, disponible en: <http://bit.ly/1OFxFaW> [Última consulta,13 de septiembre de 2018].

GMOSERALINI. "Republicación del estudio de Séralini: la ciencia habla por sí misma". Recurso electrónico, publicado el 24 de junio de 2014, disponible en: http://bit.ly/1 ruVJ47 [Última consulta, 11 de abril de 2018].

GONZÁLEZ, C. "Genetically Modified Organisms and Justice: The International Environmental Justice Implications of Biotechnology". Georgetown International Environmental Law Review, 2007, Vol. 19, № 4, p. 583-642.

GONZÁLEZ GUTIÉRREZ, J. "Biodiversidad agrícola y erosión genética". En: Especies exóticas invasoras en Andalucía. Talleres provinciales 2004- 2006, p. 159-167.

GONZÁLEZ VAQUÉ, L. "La aplicación del principio de precaución en la legislación alimentaria. ¿Una nueva frontera de protección al consumidor?”. Estudios sobre Consumo, №50, 1999, p. 10-26. 
GONZÁLEZ VAQUÉ, L. "El Derecho de la UE relativo a los organismos modificados genéticamente: la Comisión Europea cambia de estrategia para permitir, restringir o prohibir su cultivo". Revista de Derecho y Genoma Humano, 2010, № 33, p. 1-20.

GONZALO IGLESIA, J. "La teoría de la comunicación de riesgo". Comunicació i risc: III Congrés Internacional Associació Espanyola d'investigació de la comunicació, 2012, p. 178-237.

HERRERA IZAGUIRRE, J. A. "El principio precautorio en la era de los OMG: incertidumbre y conflicto internacional". Medio Ambiente y Derecho, Revista electrónica de Derecho Ambiental, 2005, № 12-13. Disponible en: $<$ https://bit.ly/2FGhSMy> [Última consulta, 9 de septiembre, 2018].

INTERNATIONAL SERVICE FOR THE ACQUISITION OF AGRI-BIOTECH APPLICATIONS. "Global Status of Commercialized Biotech/GM Crops: 2016". ISAAA Brief № 52, Ithaca, 2016.

LARRIÓN CARTUJO, J. "La resistencia a las razones de Pusztai. El conocimiento y la incertidumbre en la polémica sobre los organismos modificados genéticamente". Política y Sociedad, 2010, Vol. 47, № 1, p. 215230.

LLORET, E. "El principio preventivo y precautorio en el Derecho Ambiental: ¿a qué principio responde la evaluación del impacto ambiental?" Cartapacio de Derecho: Revista Virtual de la Facultad de Derecho, 2011, № 21, p. 1-30.

LOSEY, J. RAYOR, L. CARTER, M. "Transgenic pollen harms monarch larvae". Nature, 1999, Vol. 399, p. 214-215.

MAÑAS, F; PERALTA, L; RAVIOLO, J; GARCÍA, O.H; WEYERS, A; UGNIA, L; GONZÁLEZ, C.M; LARRIPA, I; GORLA, N. "Genotoxicity of glyphosate assessed by the comet assay and cytogenetic tests". Environmental Toxicology and Pharmacology. 2009, Vol. 28, № 1, p. 37-41.

MANCINI PALAMONI, G. "Il Principio di Prevenzione". AmbienteDiritto.it- Revista Giuridica Telematica, 2014, p. 1-15.

MARC, J; MULNER-LORILLON, O; BOULBEN, S; HUREAU, D; DURAND, G; BELLÉ, R. "Pesticide Roundup provokes cell division dysfunction at the level of CDK1/cyclin B activation". Chemical Research in Toxicology. 2002; Vol. 15, № 3 , p. 326-331. 
MELLADO RUIZ, L. "Derecho de la biotecnología vegetal. La regulación de las plantas transgénicas". Instituto Nacional de Administración Pública, Madrid, 2002.

MELLADO RUIZ, Lorenzo. "Bioseguridad y Derecho: La administración ante los riesgos de la tecnología de la vida". Editorial Comares, Granada, 2004.

MÉNDEZ, P. "Sobre el concepto de riesgo". Nómadas, revista crítica de Ciencias Sociales y Jurídicas, № 5, 2002. Recurso electrónico disponible en: http://webs.ucm.es/info/nomadas/5/pmendez.htm> [Última consulta, 23 de septiembre de 2018].

NORDLEE, J. TAYLOR, S. TOWNSEND, J. THOMAS, L. BUSH, R. "Identification of a Brazil-Nut allergen in transgenic soybeans". The New England Journal of Medicine, 1996, Vol. 334, № 11, p. 688-692.

NORGAARD, R; SIKOR, T. "Metodología y práctica de la agroecología", en Miguel Altieri (Dir.), Agroecología. Bases científicas para una agricultura sustentable, capítulo II. CLADES/ACAO, La Habana, 1997, p. 15-29.

OCDE. "Recombinant DNA Safety Considerations. Safety considerations for industrial, agricultural and environmental applications of organisms derived by recombinant DNA techniques". París, 1986.

PARLAMENTO DEL REINO UNIDO. "A brief outline history of the legislation on health and safety aspects of GMOs". Recurso electrónico disponible en: http://bit.ly/2ftjFpJ> [Última consulta,16 de febrero de 2018].

POULSEN, M.S; RYTTING, E; MOSE, T; KNUDSEN, L.E. "Modeling placental transport: correlation of in vitro BeWo cell permeability and ex vivo human placental perfusión". Toxicology in vitro, 2009, Vol. 23, № 7, p.1380-1386.

ROBIN, M. "El Mundo según Monsanto: de la dioxina a los OMG: una multinacional que les desea lo mejor". Editorial Península, Barcelona, 2008.

RODRÍGUEZ LÓPEZ, B. "El cuidado debido. Organismos genéticamente modificados y principio de precaución". Dilemata, 2013, № 11, p. 61-81.

RODRÍGUEZ ZABALETA, H. "Riesgo y principio de precaución. Hacia una cultura de la incertidumbre". Revista Catalana de Seguretat Pública, 2003, № 13, p. 139-161.

ROH, J.Y. CHOI, J.Y. LI, M.S. JIN, B.R. JE, Y.H. "Bacillus thuringiensis as a specific, safe, and effective tool for insect pest control". Journal of Microbiology and Biotechnology. 2007, Vol. 17, no 4, p. 547-559. 
SADELEER, N. "Environmental Principles: From Political Slogans to Legal Rules". Oxford University Press, Nueva York, 2002.

SADELEER, N. "Le principe de précaution dans le monde". Fondapol, Jean Jaures Fondation, París, 2011.

SÁNCHEZ MUÑOZ, M. "Treinta años de actuación en materia medioambiental en la Unión Europea". Comunicación presentada en el Congreso Internacional de Ordenación del Territorio, Gijón, julio de 2001.

SÉRALINI, G. CLAIR E. MESNAGE R. GRESS S. DEFARGE N. MALATESTA, M. HENNEQUIN D. SPIROUX DE VENDOMOIS, J. "Long term toxicity of a Roundup herbicide and a Roundup-tolerant genetically modified maize". Food and Chemical Toxicology, 2012, Vol. 50, Issue 11, p. 4221-4231. (Publicación original que sería posteriormente retirada).

SÉRALINI, G. CLAIR, E. MESNAGE, R. GRESS, S. DEFARGE, N. MALATESTA, M. HENNEQUIN, D. SPIROUX DE VENDOMOIS, J. "Republished study: Long term toxicity of a Roundup herbicide and a Roundup-tolerant genetically modified maize". Environmental Sciences Europe, 2014, Vol. 26, № 14, p. 2-17.

STONE, G. y GLOVER, D. "Disembedding grain: Golden Rice, the green revolution, and heirloom seeds in the Philippines". Agriculture and Human Values, 2016, Vol. 34, Issue 1, p. 87-102.

TÁBARA, D; POLO, D; LEMKOW, L. "Precaución, riesgo y sostenibilidad en los organismos agrícolas modificados genéticamente". Política y Sociedad, 2003, Vol. 40, № 3, p. 82-103.

TRUMPER, E. "Resistencia de insectos a cultivos transgénicos con propiedades insecticidas. Teoría, estado del arte y desafíos para la República de Argentina". Agriscientia, diciembre 2014, Vol. 31, № 2, p. 109-126.

TSATSAKIS, A. NAWAZ, M. TUTELYAN, V. GOLOKHVAST, K. KALANTZI, O. CHUNG, D. KANG, S. COLEMAN, M. TYSHKO, N. YANG, S. CHUNG, G. "Impact on the environment, ecosystem, diversity and Health from culturing and using GMO as feed and food". Food and Chemical Toxicology, 2017, p. 1-64.

UNEP, CDB, OMS. "Connecting Global Priorities: Biodiversity and Human Health. A State of Knowledge Review". OMS Library, Ginebra, 2015. 
WAIGMANN, E; PAOLETTI, C; DAVIES, H; PERRY, J; KÄRENLAMPI, S; KUIPER, H. "Risk assessment of Genetically Modified Organisms (GMOs)". EFSA Journal, 2012; Vol. 10, №10, Special Issue 1008, p. 1-7.

WOEGERBAUER, M; ZEINZINGER, J; GOTTSBERGER, R; PASCHER, K; HUFNAGL, P; INDRA, A; FUCHS, R; HOFRICHTER, J; KOPACKA, I; KORSCHINECK, I; SCHEILER, C; SCHWARZ, M; STEINWIDER, J; SPRINGER, B; ALLERBERGER, F; NIELSEN, K; FUCHS, K. "Antibiotic resistance marker genes as environmental pollutants in GMO-pristine agricultural soils in Austria". Environmental Pollution, 2015, № 206, qp. 342-351.

YOKE HEONG, Ch. "Alimentos transgénicos y bioseguridad. Descubrimientos científicos siembran alarma". Revista del Sur, junio de 1999, № 92. 